Article

\title{
Deciphering the Novel Role of AtMIN7 in Cuticle Formation and Defense against the Bacterial Pathogen Infection
}

\author{
Zhenzhen Zhao ${ }^{1}$, Xianpeng Yang ${ }^{2}{ }^{\circledR}$, Shiyou L $\ddot{u ̈}^{3}$, Jiangbo Fan ${ }^{4}$, Stephen Opiyo ${ }^{1}$, Piao Yang ${ }^{1}{ }^{(}$, \\ Jack Mangold ${ }^{1}$, David Mackey ${ }^{5}$ and Ye Xia ${ }^{1, * \mathbb{D}}$ \\ 1 Department of Plant Pathology, College of Food, Agricultural, and Environmental Science, The Ohio State \\ University, Columbus, OH 43210, USA; zhao.2047@osu.edu (Z.Z.); opiyo.1@osu.edu (S.O.); \\ yang.4636@osu.edu (P.Y.); mangold.20@buckeyemail.osu.edu (J.M.) \\ 4 School of Agriculture and Biology, Shanghai Jiao Tong University, Shanghai 200240, China; \\ fan.0127@yahoo.com \\ 5 Department of Horticulture and Crop Science, College of Food, Agricultural, and Environmental Science, \\ The Ohio State University, Columbus, OH 43210, USA; mackey.86@osu.edu \\ * Correspondence: xia.374@osu.edu
}

Received: 15 July 2020; Accepted: 1 August 2020; Published: 3 August 2020

\begin{abstract}
The cuticle is the outermost layer of plant aerial tissue that interacts with the environment and protects plants against water loss and various biotic and abiotic stresses. ADP ribosylation factor guanine nucleotide exchange factor proteins (ARF-GEFs) are key components of the vesicle trafficking system. Our study discovers that AtMIN7, an Arabidopsis ARF-GEF, is critical for cuticle formation and related leaf surface defense against the bacterial pathogen Pseudomonas syringae pathovar tomato (Pto). Our transmission electron microscopy and scanning electron microscopy studies indicate that the atmin 7 mutant leaves have a thinner cuticular layer, defective stomata structure, and impaired cuticle ledge of stomata compared to the leaves of wild type plants. GC-MS analysis further revealed that the amount of cutin monomers was significantly reduced in atmin 7 mutant plants. Furthermore, the exogenous application of either of three plant hormones-salicylic acid, jasmonic acid, or abscisic acid-enhanced the cuticle formation in atmin 7 mutant leaves and the related defense responses to the bacterial Pto infection. Thus, transport of cutin-related components by AtMIN7 may contribute to its impact on cuticle formation and related defense function.
\end{abstract}

Keywords: plant cuticle; cutin; vesicle trafficking; transport; plant hormones; plant defense

\section{Introduction}

The plant cuticle is the outermost hydrophobic layer of the aerial plant surfaces which functions as a mechanical barrier to provide physical support, avoid organ fusion, and control the surface water status [1,2]. The cuticle, which covers most of the plant tissues, including the leaves, fruits, flowers, and non-woody stems, is the first line to contact the outside environment [3-5]. The cuticle protects plants against various abiotic and biotic stresses, including extreme temperatures, drought, UV radiation, and attacks by pathogens and insects. The status of the cuticle varies with the stage of plant development as well as environmental factors. For instance, a pathogen's entry into the plant tissue is the critical first step during the infection process, which leads to compositional and functional changes of the cuticle. Conversely, pathogens can sense the changes of the plant cuticle and adjust 
their pathogenesis and virulence accordingly [6,7]. Emerging research indicates that the plant cuticle participates in preemptive plant defense, such as during systemic acquired resistance (SAR) [7-9]. However, the regulation and role of the cuticle in plant defense are still poorly understood.

With the development of genetic, molecular, and biochemical approaches, we have a better understanding of the components and mechanisms involved in cuticle biosynthesis and related functions in the past decade. Plant cuticles are mainly composed of cutin and cuticular waxes. In Arabidopsis, cutin is a core structural polymer of hydroxy and/or epoxy fatty acids. The cuticular wax covering the cutin matrix is a complex mixture consisting of very long-chain fatty acid (VLCFA) derivatives, including alkanes, aldehydes, primary and secondary alcohols, ketones, and esters $[1,3,10]$. Cutin and wax biosynthesis both begin with the de novo C16 and C18 fatty acids in the plastid of plant epidermal cells. Plastid-generated C16 and C18 fatty acids are esterified to Co-enzyme A (CoA) to form C16/18-CoA before entering the endoplasmic reticulum (ER). In ER, the C16/18-CoA is converted either to very long-chain Acyl-CoA, which are precursors for wax biosynthesis, or to 16-OH C16/18-CoA, which are precursors for cutin biosynthesis. The wax and cutin precursors must be further modified and exported from the ER, move across the plasma membrane (PM) and the polysaccharide cell wall, and ultimately self-assemble and deposit into the cuticle layer $[3,10,11]$.

The transport of cutin- and wax-related components can be divided into intracellular (translocation from the ER to the PM) and extracellular (translocation through the cell wall to the cuticle layer) trafficking [1,3]. A variety of mechanisms have been suggested for the intracellular transport of wax and cutin components, including the direct physical ER-PM contacts; transport of wax- and cutin-related components by soluble cytosolic proteins, such as LTPs (lipid transfer proteins) and fatty acid binding proteins; self-assembly to form oleophilic droplets that bud out of the ER to PM; and a Golgi or trans-Golgi network-mediated secretory pathway [1,12-16]. The export of the cuticular component translocation across the PM to the extracellular space is predicted to be carried out by ATP-binding cassette (ABC) transporters and LTPs $[13,17]$. For instance, CER5, also known as ABCG12, is required for wax export in Arabidopsis [18]. ABCG11 is required for both cutin and wax extracellular export [19]. Another transporter, ABCG13, is critical for cutin deposition in Arabidopsis flowers [20,21]. Glycosylphosphatidylinositol-anchored lipid transfer proteins 1 and 2 (LTPG1 and LTPG2), which bind to a variety of lipid substances, were found to participate in the export of wax-related components [22]. Still, the mechanisms of transporting cuticle-related components need to be further investigated.

Vesicle trafficking, which mediates the transport of materials between different cellular compartments and between a cell and its environment, is critical for plant growth, development, and responses to the environmental factors, including the defense against pathogen infections [23,24]. There are two categories of trafficking at the plasma membrane: exocytosis secretes vesicle contents to the extracellular space, and endocytosis imports extracellular materials into intracellular vesicles [23]. Upon interactions with the pathogenic microbes, endocytosis regulates the activity of surface-localized immune receptors $[25,26]$. Meanwhile, the components for cell wall fortification, antimicrobial compounds, and defense proteins are delivered to the pathogen invasion sites through polarized exocytosis [24,27]. In plants, the trans-Golgi network/early endosome (TGN/EE), which serves as a key sorting station at the intersection of exocytic and endocytic pathways, plays a critical role in sorting and delivery of the soluble defense proteins to the extracellular space or the membrane localized cargo to PM during the immune activation $[23,28]$. Several important components of TGN/EE are involved in the trafficking of specific immune-related cargoes [29]. For instance, the TGN/EE-localized E3 ubiquitin ligase Keep On Going plays a critical role in sorting and delivering of the pathogenesis-related protein 1 and papain-like Cys protease C14 to the extracellular space [30]. The TGN/EE-resident SNARE protein VAMP721/722 was found to regulate the delivery of RPW8.2, a key protein in resistance against the powdery mildew pathogen, to the extrahaustorial membrane, which is the fungal pathogen feeding structure [31]. Clathrin-coated vesicles (CCVs) contribute to immune cargo trafficking, which regulates the plant immune responses [32]. However, little is known about the defense-associated trafficking of cuticular wax and cutin components to the cuticle layer. 
ADP ribosylation factor guanine nucleotide exchange factors (ARF-GEFs) are the key components of the vesicle trafficking system [33,34]. AtMIN7, one of eight ARF-GEFs in Arabidopsis, is localized to the TGN/EE where it regulates the plant resistance against Pseudomonas syringae pathovar tomato DC3000 (Pto DC3000) [35-38]. ARF proteins switch between the active (GTP-bound) and inactive (GDP-bound) states. Upon activation, ARFs bind to membranes and promote vesicle budding at the TGN, endosomal compartments, and PM [39,40]. Highlighting the importance of AtMIN7 for plant immunity, the HopM1 virulence effector from Pto DC3000 contributes to bacterial virulence by interacting with and triggering proteasome-mediated degradation of AtMIN7 [35,36].

In this study, we found that atmin 7 mutant plants are defective in cuticle formation by toluidine blue staining and direct observation with transmission electron microscopy (TEM) and scanning electron microscopy (SEM). Consistent with these observations, GC-MS analysis showed that cutin monomer contents were specifically reduced in mutant leaves. Furthermore, it was discovered that the exogenous application to atmin 7 mutant leaves of either of three plant hormones-salicylic acid (SA), jasmonic acid (JA), or abscisic acid (ABA)—could enhance the cuticle formation and restore leaf surface defense responses against Pto DC3000. Taken together, our results indicate that AtMIN7 is critical for cutin formation, perhaps by supporting the transport of precursor subunits and/or related enzymes. Furthermore, AtMIN7 may integrate the response to hormones with modification of the cuticle for the defense against Pto DC3000 infection in Arabidopsis.

\section{Results}

\subsection{Molecular Perturbation of AtMIN7}

Arabidopsis encodes eight ARF-GEFs, each of which contains a Brefeldin A (BFA)-inhibited Sec7 catalytic domain that activates ARF proteins by exchanging GDP for GTP [40]. These are divided into two subfamilies: the GGG class which includes GNOM, GNOM-LIKE1(GNL1), and GNL2; and the BIG (BFA-inhibited guanine nucleotide exchange proteins) class which includes five members (BIG1-5) [39]. To investigate their relationships, a multiple protein sequence alignment of all eight ARF-GEFs isoforms was created using Clustal Omega (https://www.ebi.ac.uk/Tools/msa/clustalo/). AtMIN7/BIG5 does not cluster with the other four BIG isoforms (Figure 1a), which indicates that it might have a unique function.

The T-DNA insertion line of AtMIN7 (AT3G43300) (Salk_013761) was obtained from the Arabidopsis Biological Resource Center in USA and the homozygous line was identified based on the protocol developed by the Salk Institute Genomic Analysis Laboratory (http://signal.salk.edu/ tdnaprimers.2.html). This mutant line, designated as atmin7 [35], has a T-DNA insertion in the 21st exon (Figure 1b). The abundance of the AtMIN7 transcript was much lower in atmin7 than in WT Col-0 plants (Figure 1c). To further confirm the function of AtMIN7, an atmin7 transgenic complementation line with a transgene containing the whole cDNA sequence of AtMIN7 driven by a 35S promoter (35S::MIN7-GFP) was obtained from Dr. Shengyang He's lab [35,36]. The transcript level of AtMIN7 in the complementation line was similar to that of WT plants (Figure 1c). According to the Arabidopsis eFP Browser (http://bar.utoronto.ca/eplant/), AtMIN7 is constitutively and highly expressed in stems, leaves, roots, and flowers (Figure S1). Macroscopic examination did not reveal any differences between the atmin 7 mutant, complementation line, and WT plants (Figure 1d). 
(a)

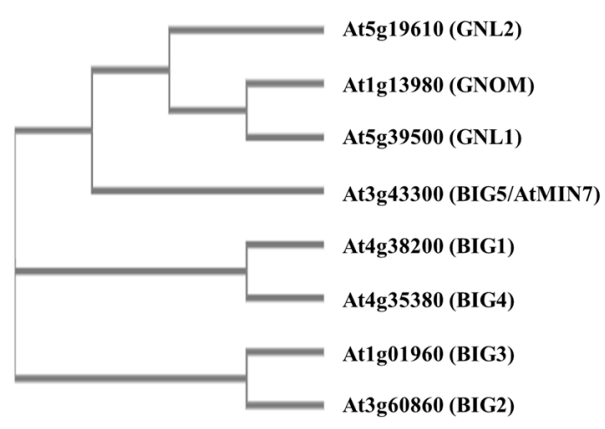

(c)

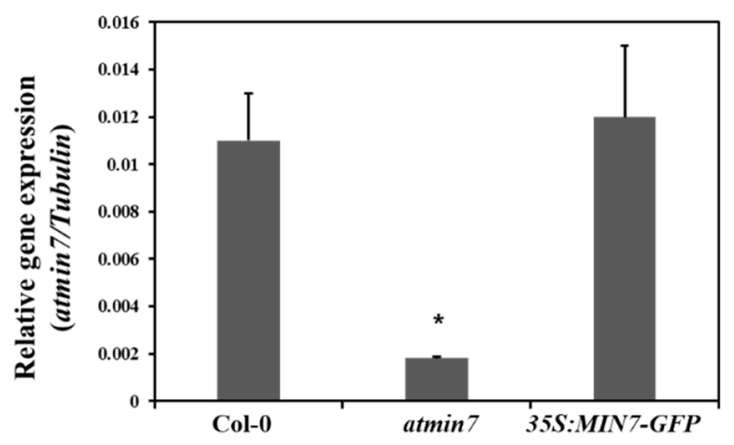

(b)

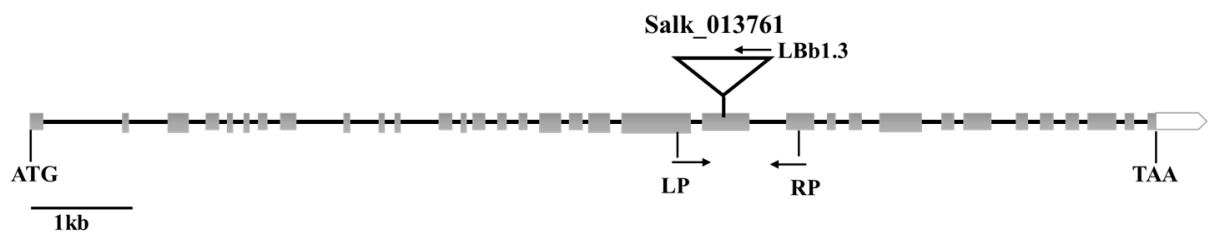

(d)

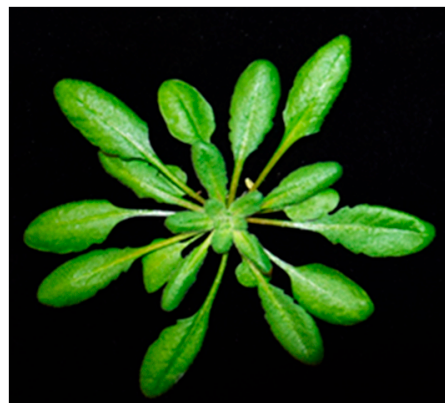

Col-0

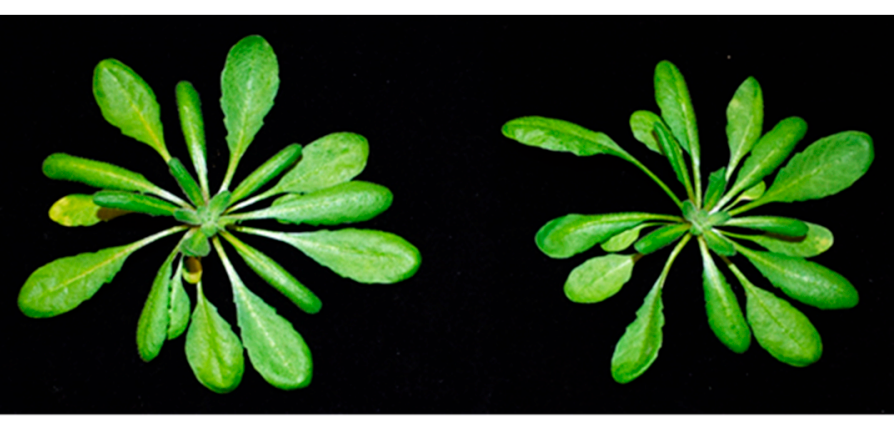

atmin 7
35S::MIN7-GFP

Figure 1. Characterization of the atmin7 mutant. (a). Phylogenetic analysis of the ARF-GFF protein family in Arabidopsis. (b). Schematic representation of the T-DNA insertion site in atmin7 mutant. Heavy black lines and gray rectangles indicate introns and exons, respectively. The T-DNA insertion site for Salk_013761 is shown. The position and orientation of primers used for qRT-PCR are indicated. (c). Relative AtMIN7 transcript abundance in the WT, atmin7, and 35S::MIN7-GFP plants. The experiment was repeated three times with similar results and the mean +/-SD for the combined data from three replicates are shown. Unpaired two-tailed Student's $t$-tests with WT plants indicated that the transcript level of AtMIN7 was significantly reduced in atmin7 but not 35S::MIN7-GFP $\left({ }^{*} p<0.01\right)$. (d). Morphological phenotype did not differ between vegetative rosettes of four-week-old WT, atmin7, and 35S::MIN7-GFP plants.

\subsection{A Mutation in AtMIN7 Results in the Defective Cutin Layer and Stomata Ledge}

Toluidine blue (TB) is a hydrophilic dye that more efficiently penetrates leaves with a defective cuticle [41]. TB staining of four-week-old WT, atmin7, and 35S::MIN7-GFP plants indicated a defective cuticle in the leaves of atmin7 plants (Figure 2a). A defective cuticle results in faster chlorophyll leaching in $80 \%$ ethanol $[9,42]$. Consistent with the results of TB staining, chlorophyll leached faster from the atmin 7 leaves compared to those of the WT and complementation line (Figure 2b). 


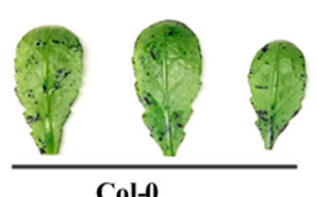

Col-0

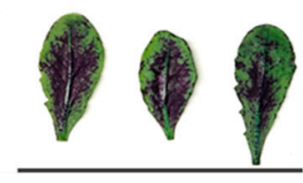

$\operatorname{atmin} 7$

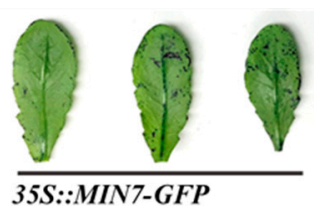

(a)

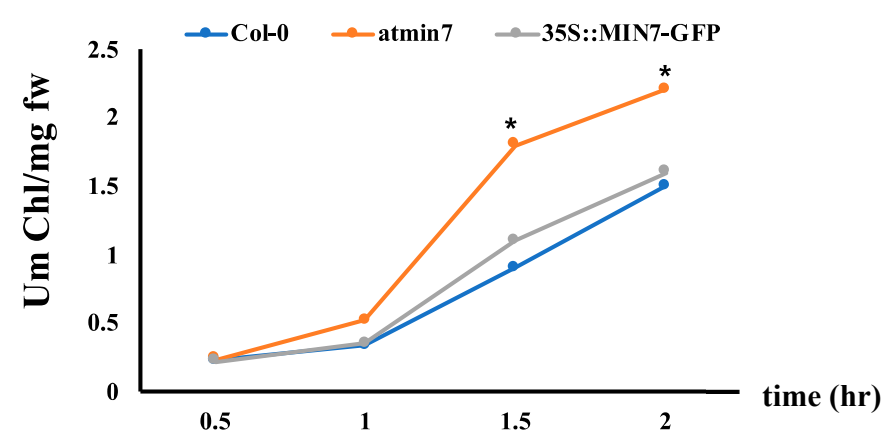

(b)

Figure 2. AtMIN7 is required for the normal cuticle formation. (a). Leaves of four-week-old WT Col-0, atmin7, and 35S::MIN7-GFP complementation plants stained with TB. The mutant atmin7 plants showed the TB staining but not the WT and 35S::MIN7-GFP complementation plants, which indicated the defective cuticle in atmin 7 mutant plants. (b). Chlorophyll leaching rate of the leaves of WT (blue circles), atmin7 (orange circles), and 35S::MIN7-GFP (grey circles) plants. The experiment was repeated three times with the similar results and mean $+/$ SD for the combined data from three replicates are shown. Unpaired two-tailed Student's $t$-tests with WT plants indicated that chlorophyll leaching did not differ from 35S::MIN7-GFP but was significantly increased at 1.5 and $2 \mathrm{~h}$ in atmin 7 plants $\left({ }^{*} p<0.05\right)$, which indicated the defective cuticle in the atmin 7 mutant plants.

Further analysis by TEM indicated that the cuticle layer of atmin 7 was much thinner than the WT plants (Figure 3a). The cuticular ledge is the outermost layer of the stomata pore, which regulates stomatal function $[43,44]$. TEM also demonstrated that the cuticular ledge of stomata in atmin 7 leaves was almost missing (Figure 3b). SEM was also used to compare the leaf surface of atmin7 and WT plants. The overall structure of stomata in the leaves of atmin 7 plants, especially the guard cells, was defective compared to those in WT plants (Figure 3c). Randomly selected stomata on both the adaxial (upper) and abaxial (lower) sides of leaves showed the defective structure approximately three times more frequently in atmin7 than in WT plants (Figure 3d). Pavement cells of the adaxial surfaces of the WT leaves showed the regular puzzle shape while those of atmin 7 leaves contained irregular lobes (Figure 3e). Similarly, epidermal cells on the abaxial surface of atmin7 leaves were less interconnected relative to the pattern in WT leaves. Furthermore, observation of leaf cross-sections by SEM revealed that the epidermal cells were collapsed in atmin7 relative to WT plants (Figure S2). Altogether, a mutation in AtMIN7 resulted in various defects of the plant leaf surface, especially the cuticle of leaf surfaces and the cuticular ledge of stomata. 
(a)
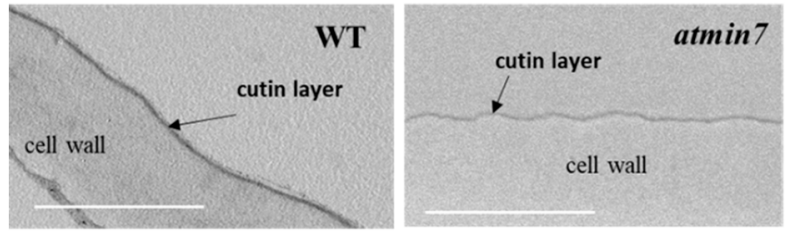

(b)
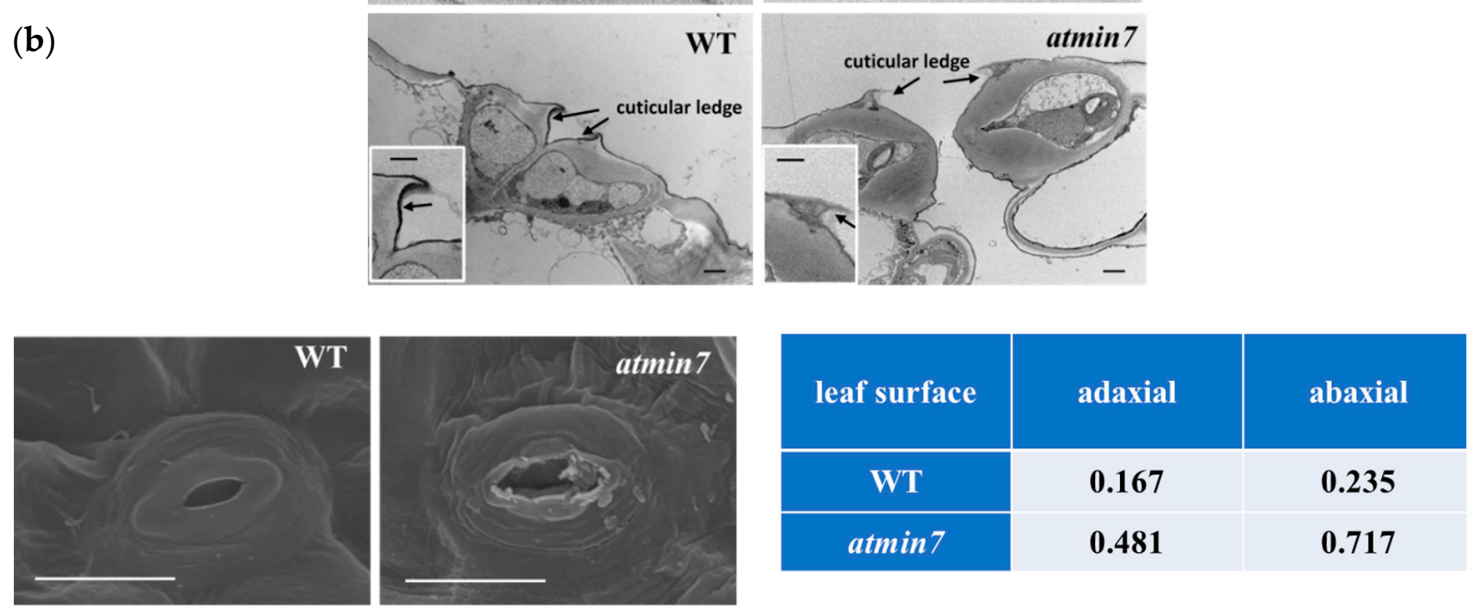

(c)

(d)
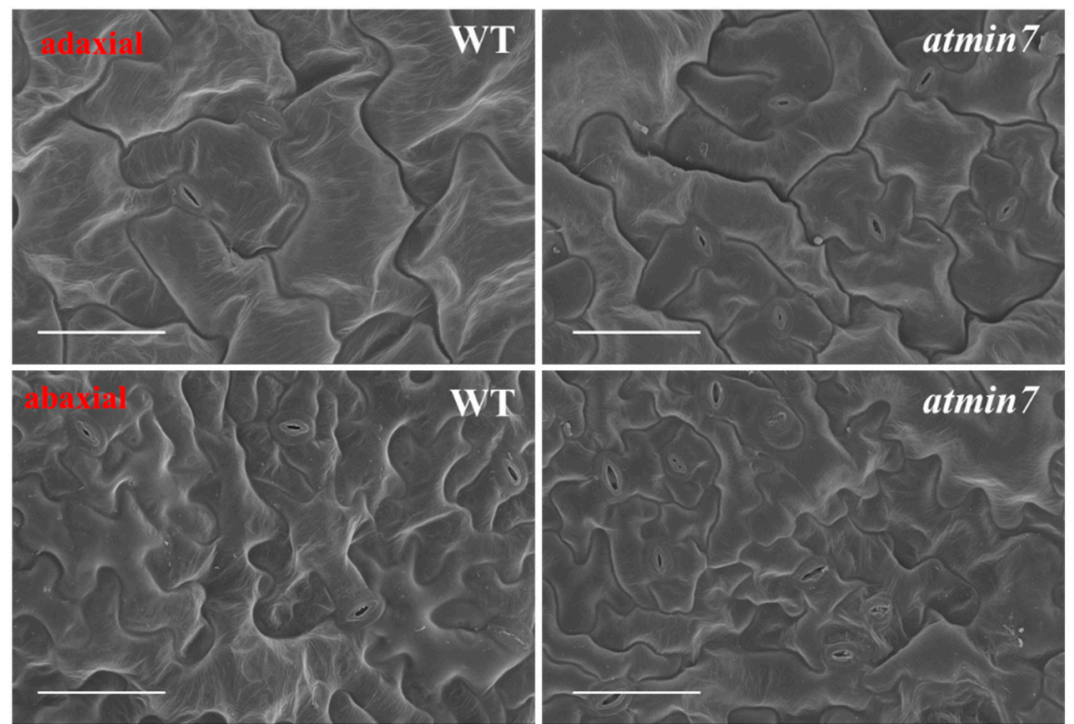

(e)

Figure 3. TEM and SEM reveal the defective cuticle and stomatal structure in the leaves of atmin7 plants. (a). TEM images of the cutin layer (indicated by black arrows) on adaxial surfaces of WT and atmin 7 leaves (scale bars $=1 \mu \mathrm{m}$ ). (b). TEM images of the transdermal sections of leaf guard cells. Black arrows indicate the cuticular ledges (scale bars $=1 \mu \mathrm{m}$ ). Insets are magnified images of the cuticular ledges (scale bars $=1 \mu \mathrm{m}$ ). (c). SEM images of stomata from abaxial surface of leaves from WT and atmin 7 mutant plants (scale bars $=10 \mu \mathrm{m}$ ). (d). Frequency of defective stomata on WT and atmin 7 leaf surface (adaxial and abaxial) detected by SEM (randomly selected 60 stomata for each group). (e). SEM images of adaxial and abaxial leaf surface of WT and atmin7 leaves (scale bars $=50 \mu \mathrm{m}$ ).

\subsection{The Abundance of Cutin Monomers Is Reduced in the Atmin7 Mutant Plants}

In addition to the direct observations of the cuticle layer, the leaf cuticular wax and cutin monomer contents were measured by GC-MS. The total leaf cuticular wax load and wax compositions of leaves of atmin7 did not differ significantly from those of WT plants (Figure 4a). Analysis of the chemical 
composition of cutin monomers revealed significant reductions in the total levels of cutin monomers in the leaves of atmin 7 relative to those of WT plants, including the major cutin monomer, C18:2 dioic acid, as well as two less abundant cutin monomers, 16-OH-C16:0 acid and C18:1 dioic acid (Figure 4b). The wax compositions and levels of cutin monomers did not significantly differ between WT plants and the complementation line (Figure $4 \mathrm{a}, \mathrm{b}$ ). The significant decrease in the total cutin monomers, including several cutin monomer species, is consistent with the altered ultrastructure of the whole cuticle layer and the cuticular ledge of the stomatal pores in the atmin 7 leaves. Therefore, the mutation of AtMIN7 significantly influences cutin, but not wax, formation in Arabidopsis leaves.
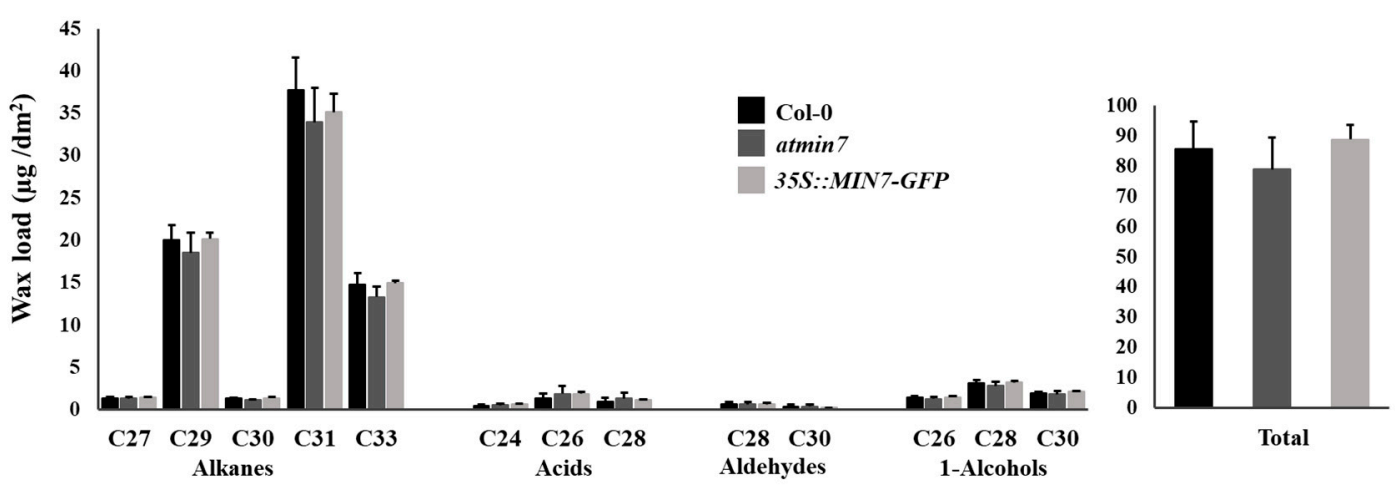

(a)
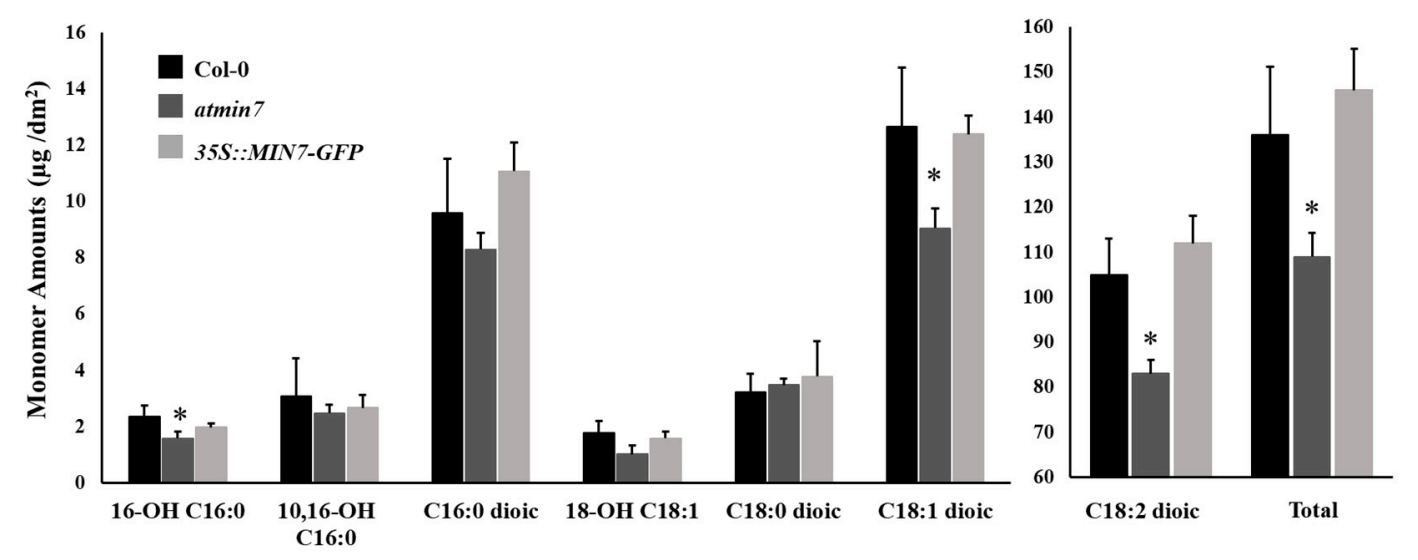

(b)

Figure 4. The content of cutin monomers, but not cuticular wax, is abnormal in the leaves of atmin7 mutant plants. (a). Wax load with different chain lengths and total content in the leaves of WT, atmin7, and 35S::MIN7-GFP plants are shown as mean +/- SD. Unpaired two-tailed Student's $t$-tests with WT did not show significant differences to atmin 7 or 35S::MIN7-GFP plants $\left({ }^{*} p<0.05\right)$. (b). The abundance of cutin monomers and total content in the leaves of WT, atmin7, and 35S::MIN7-GFP plants are shown as mean +/- SD. The C16 and C18 labels on the $x$-axis represent the 16- and 18-carbon acid chains, respectively, whereas the number preceding " $\mathrm{OH}^{\prime}$ indicates the chain insertion point(s). Dioic represents dioic acid. Unpaired two-tailed Student's $t$-tests with WT show significant differences versus atmin 7 and complementation line plants $\left({ }^{*} p<0.05\right)$.

2.4. The Atmin7 Mutant Plants Display Increased Susceptibility Following the Bacterial Infection of the Leaf Surface

Whether the defective cuticle of atmin 7 mutant plants alters the defense against the infection with Pto was investigated. WT, atmin7, and 35S:: MIN7-GFP plants were inoculated with Pto DC3000 bacterial cells via either of two methods, infiltration with a needleless syringe or surface spray, and the bacterial growth was assessed three days later. The growth of Pto DC3000 did not differ between WT and atmin7 
or 35S::MIN7-GFP plants following the syringe infiltration (Figure 5a). However, the atmin7 mutant was more susceptible than WT and 35S::MIN7-GFP when plants were spray-inoculated (Figure 5b). The enhanced susceptibility of atmin 7 following the infection of Pto initiating on the leaf surface, but not the leaf interior, is consistent with a role of AtMIN7-dependent stomata and cuticle structure in leaf surface defense [45].

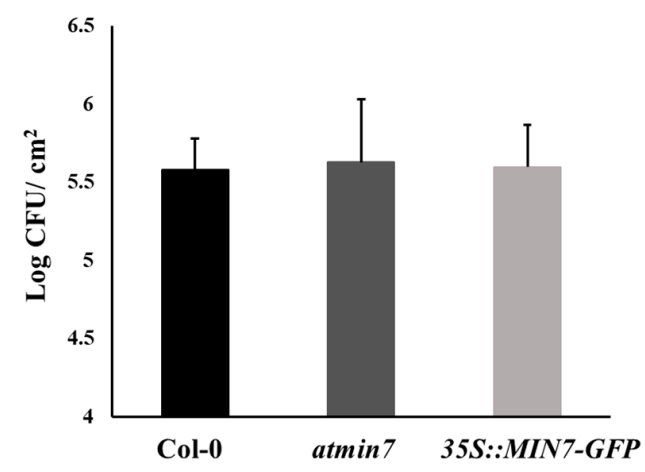

(a)

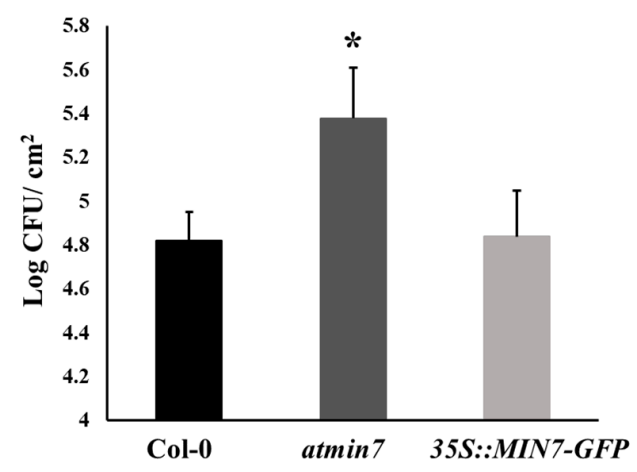

(b)

Figure 5. The atmin 7 mutant plants are more susceptible to the Pto DC3000 infection on the leaf surface by the spray treatment but not the syringe infiltration. (a). Bacterial multiplication in the leaves of WT, atmin7, and 35S::MIN7-GFP plants following the syringe infiltration with $1 \times 10^{5} \mathrm{CFU} / \mathrm{mL}$ of Pto DC3000. (b). Bacterial multiplication in the leaves of WT, atmin7, and 35S::MIN7-GFP plants following the surface spray with $1 \times 10^{8} \mathrm{CFU} / \mathrm{mL}$ of Pto DC3000. Following each inoculation method, bacteria were enumerated three days after the infection. The experiments were repeated three times with similar results, and the mean +/- SD for the combined data from three biological replicates are shown. Unpaired two-tailed Student's $t$-tests with WT plants only revealed a significant difference with atmin 7 following the Pto DC3000 infection by surface spray $\left({ }^{*} p<0.05\right)$.

\subsection{Plant Hormones Rectify the Cuticle Formation and Defense Phenotypes in Atmin7 Mutant Plants}

Plant hormones regulate plant growth and development processes, such as cell division, elongation, differentiation, and pattern formation, as well as plant responses to biotic and abiotic stresses [46,47]. Previous studies highlighted the possibility that plant hormone influence cuticle formation [7,48-50]. Here, atmin 7 and WT plants were sprayed with different plant hormones [SA $(1 \mathrm{mM})$, JA $(50 \mu \mathrm{M})$, ABA $(50 \mu \mathrm{M})$, gibberellic acid $\left(\mathrm{GA}_{3}, 100 \mu \mathrm{M}\right)$, and indole-3-acetic acid (IAA, 10 $\left.\left.\mu \mathrm{M}\right)\right]$. $24 \mathrm{~h}$ later, the leaves were stained with TB. Application of $\mathrm{SA}$, JA, or ABA, but not water, $\mathrm{GA}_{3}$ or IAA, restored the resistance to $\mathrm{TB}$ staining in atmin 7 plants, indicating that $\mathrm{SA}, \mathrm{JA}$, and $\mathrm{ABA}$ could rescue the cuticle formation within one day of their application to atmin7 plants (Figure 6a and Figure S3).

We further investigated if the enhanced cuticle formation by SA, JA, and ABA could increase the resistance of atmin 7 mutant plants following the surface inoculation with Pto DC3000. Plant leaves were sprayed with SA $(1 \mathrm{mM})$, JA $(50 \mu \mathrm{M})$, or ABA $(50 \mu \mathrm{M})$ and $24 \mathrm{~h}$ later, they were spray-inoculated with Pto DC3000. The bacterial growth was then measured three days later. Arabidopsis plants upregulate SA signaling and repress JA signaling during the successful defense against hemi-biotrophic strains of Pto [45]. Similar to JA, ABA also increases the susceptibility of the plants to Pto infection [45,51]. As expected, we observed that treatment with SA increased and treatment with JA or ABA decreased the resistance of WT and 35S::MIN7-GFP plants to the Pto DC3000 infection (Figure 6b-d). In atmin7 mutant plants, SA and ABA treatments also increased or decreased, respectively, plant resistance to Pto DC3000, while an effect of JA was not observed (Figure 6b-d). Notably, the magnitude of enhanced susceptibility of atmin7 plants, relative to WT and 35S::MIN7-GFP plants, was reduced following the treatments with SA or JA, and was no longer significant following the treatment with ABA (Figure $6 \mathrm{~b}-\mathrm{d}$ ). This result is consistent with the hypothesis that restoration of the cuticle by these plant hormones concomitantly restores leaf surface defense against Pto DC3000. 


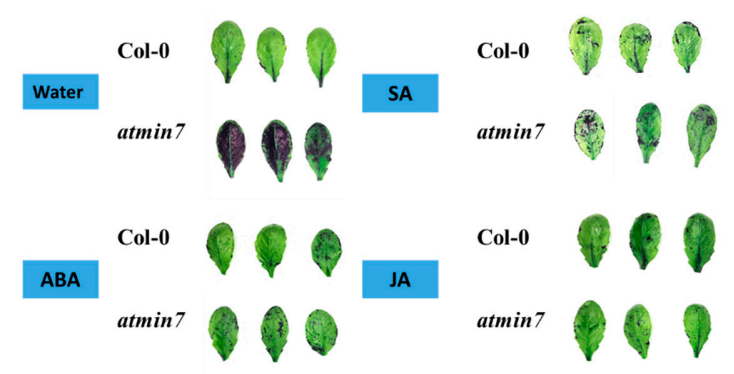

(a)

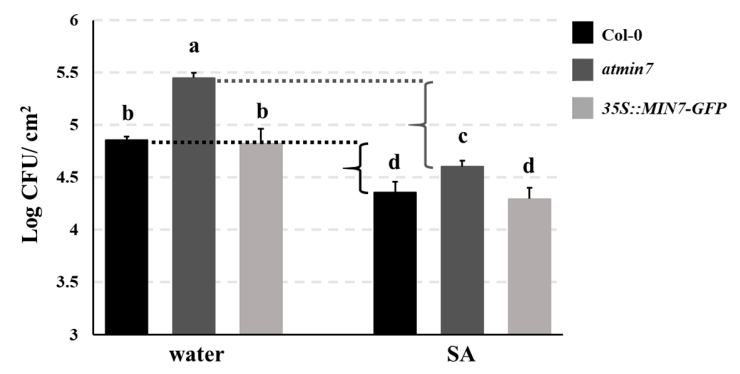

(b)

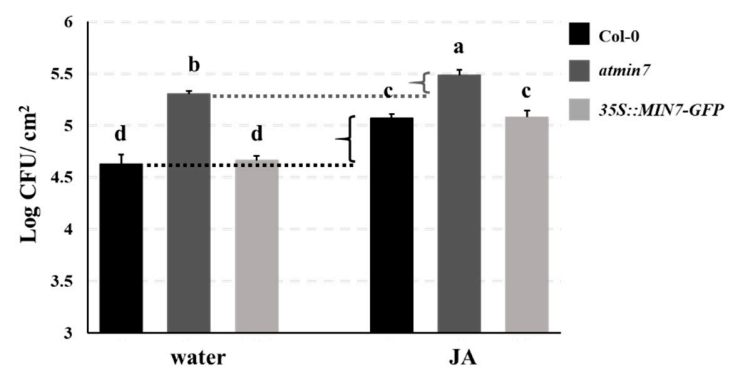

(c)

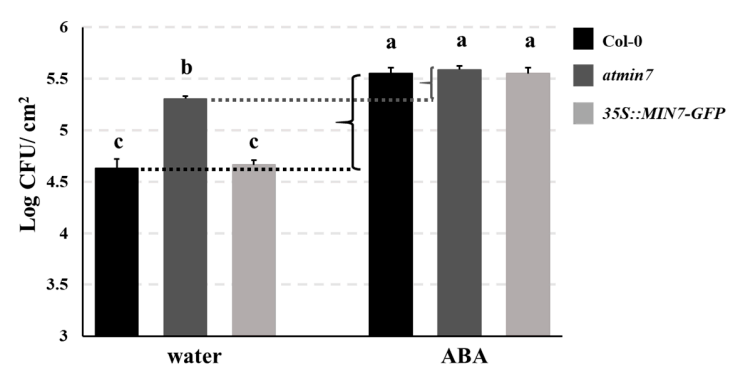

(d)

Figure 6. The plant hormones SA, JA, and ABA rescue cuticle formation and defense against the surface infection with Pto DC3000 in atmin7 mutant plants. (a). Leaves of four-week-old WT or atmin 7 plants were stained with TB $24 \mathrm{~h}$ after the spray treatment with water, SA ( $1 \mathrm{mM}), \mathrm{JA}(50 \mu \mathrm{M})$, ABA $(50 \mu \mathrm{M}) .100 \% \mathrm{EtOH}(500 \mu \mathrm{L})$ was firstly used to dissolve SA, JA, and ABA, which were further diluted with $1 \mathrm{~L}$ distilled and deionized water to reach the final treatment concentration, respectively. Accordingly, 1L distilled and deionized water with an equivalent amount of $100 \% \mathrm{EtOH}(500 \mu \mathrm{L})$ was sprayed as the control. (b-d). WT, atmin7, and 35S::MIN7-GFP plants were sprayed with water control and either SA (b), JA (c), or ABA (d) as in the panel. $24 \mathrm{~h}$ later, the plant leaves were spray inoculated with $1 \times 10^{8} \mathrm{CFU} / \mathrm{mL}$ of $P$ to DC3000. Three days later, the bacteria were enumerated. The experiment was repeated twice with similar results, and the mean $+/-$ SD of combined data from the two biological replicates are shown. Different letters a-d within figure $(\mathbf{b}-\mathbf{d})$ indicate the significant differences at $p<0.05$, which was calculated by one-way analysis of variance (ANOVA) using SPSS ver. 21. 
We further determined whether the mutation of AtMIN7 influenced the levels of SA, JA, and ABA. The quantification of free SA, SA-Gly (an inactive glycosylated derivative of salicylic acid), free JA, biologically active conjugated JA (JA-Ile/Leu), and ABA revealed that the leaves of atmin7 mutant plants contained significantly lower levels of free SA and JA, JA-Ile/Leu, and ABA compared to the WT plants (Figure 7a-d). Thus, the ability of these hormones to restore the cuticle formation in the atmin 7 mutant may be related to their constitutively low levels in the leaves of the atmin 7 mutant, relative to WT plants.

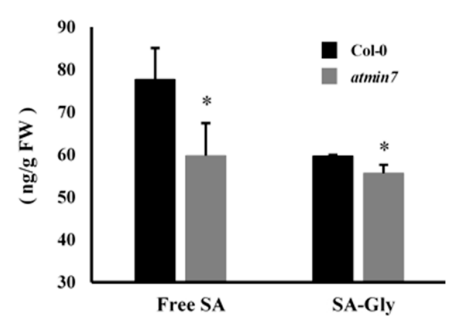

(a)

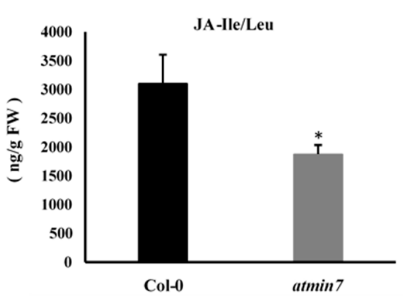

(c)

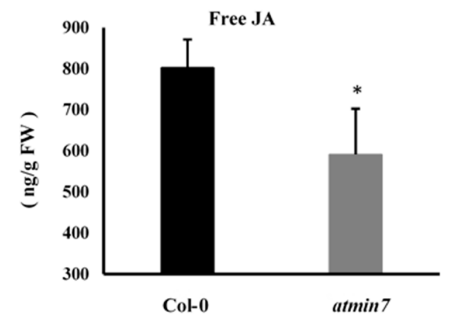

(b)

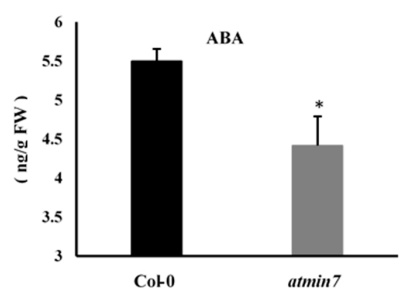

(d)

Figure 7. The atmin7 mutant plants accumulated lower levels of salicylic acid (SA), jasmonic acid (JA), and abscisic acid (ABA) relative to WT Col-0 plants. The levels of free SA and SA-Gly (a), free JA (b), JA-Ile/Leu (JA-isoleucine/leucine) (c), and ABA (d) were quantified in the leaves of four-week-old WT and atmin 7 plants. The experiment was repeated twice with similar results, and the mean $+/-$ SD from the two biological replicates are shown. Significant differences between WT and atmin 7 plants were determined by Student's $t$-test $\left({ }^{*} p<0.05\right)$. FW indicates the fresh weight.

\subsection{Transcriptome Analysis of the Atmin7 Mutant Plants}

We conducted RNA-Seq to determine the difference in the transcriptome between the leaves of four-week-old atmin 7 and WT plants [2]. A $p$-value of $<0.05$ and $\mid \log 2$ fold change (FC) $\mid \geq 2$ were used as the stringent cutoff criteria to designate genes as differentially expressed (DEGs). Based on the criteria, 198 DEGs were downregulated in atmin7 compared to WT plants (Supplemental Table S1). Given its contribution to cuticle formation, we hypothesize that AtMIN7 mediates the trafficking of cutin building blocks or key enzymes involved in cutin biosynthesis. In addition to this putative direct role of AtMIN7 in cutin formation, many genes hypothetically involved in cutin biosynthesis were downregulated in atmin7 (Table S2). The cutin precursor used for the extracellular polymerization is thought to be a monoacylglycerol (MAG), likely a 2-MAG [52]. Glycerol-3-phosphate-acyltransferases (GPAT) are involved in the biosynthesis of 2-MAG [53]. Specifically, GPAT4 and GPAT6 catalyze the acyl-transfer or hydrolase reactions important for cutin biosynthesis [54,55]. Notably, GPAT5 and GPAT7 were significantly downregulated relative to WT in atmin7 plants (AT3G11430, 3.80-fold; AT5G06090, 4.68-fold), which might be related to the inhibition of cutin biosynthesis. GDSL-lipases (Gly-Asp-Ser-Leu family of esterases/acylhydrolases) are also required for the formation of cutin polymers [56]. Genes hypothetically encoding two GDSL-lipases were downregulated relative to WT in atmin7 plants (AT3G50400, 5.68-fold; AT2G23540, 3.00-fold). ABCGs are critical components for the extracellular transport of cuticular wax and cutin from the ER to the cell wall and cuticular layer [21,57,58], and ABCG6 was downregulated relative to WT in atmin7 plants (AT5G13580, 2.13-fold). 
Transcription factors of MYB family are known to regulate wax and cutin biosynthesis in response to biotic and abiotic stresses [59-64]. MYB96 and MYB94 were identified to be involved in the activation of wax biosynthesis by drought or ABA treatment [60,63]. MYB30 modulated the plant resistance to avirulent Pto strains infection by affecting the very long-chain fatty acid (VLCFA) and VLCFA derivatives (wax components) biosynthesis [59,61]. MYB106, together with MYB16, participates in the cutin biosynthesis in Arabidopsis [62]. MYB41 could be induced by drought, ABA, and salt stress. Overexpression of MYB41 in Arabidopsis plants lead to the downregulation of cutin biosynthesis related genes expression and defective cuticle structure [64]. Our transcriptome data revealed that several $M Y B$ transcription factors genes were significantly downregulated relative to WT in atmin7 plants (MYB41, AT4G28110, 4.42-fold; MYB114, AT1G66380, 4.67-fold; MYB49, AT5G54230, 4.42-fold; MYB17, AT3G61250, 2.80-fold; MYB75, AT1G56650, 2.29-fold), suggesting their possible role in the regulation of cuticle biosynthesis. Lipid transfer proteins (LTPs) and glycosylphosphatidylinositol-anchored lipid transfer proteins (LTPGs) are essential components predicted to transfer lipids or cuticle precursors to their expected destinations $[65,66]$. Several $L T P$ and $L T P G$ genes were significantly downregulated relative to WT in atmin7 mutant (LTP4, AT5G59310, 5.44-fold; LTP3, AT5G59320, 4.62-fold; LTP6, AT3G08770, 3.19-fold; LTP2, AT2G38530, 3.12-fold; LTPG15, AT2G48130, 3.50-fold; LTPG5, AT3G22600, 3.02-fold). Additionally, AT5G41040, which encodes a feruloyl-CoA transferase required for the suberin synthesis, was also downregulated in atmin7 (AT5G41040, 2.70-fold). Suberin, like cutin, is a plant cell wall-associated glycerolipid polymer that is found in the root endodermis [67]. Additionally, it was reported that a mutation in EGL3 (ENHANCER OF GLABRA 3) has reduced trichomes and abnormally patterned stomates [68,69]. The downregulation of EGL3 in atmin7 (AT1G63650, 2.14-fold) might be related with the defective stomata structure of the mutant plants. Thus, in addition to a putative direct role for AtMIN7 in transport processes required for cutin biosynthesis, changes in the transcriptome of atmin 7 plants may also contribute to the observed cuticle defects and the associated defense phenotypes.

\section{Discussion}

\subsection{Vesicle Trafficking in Plant Cuticle-Related Component Transport and Cuticle Biosynthesis}

Despite many efforts to decipher the mechanisms of cuticle biosynthesis, transport, and regulation, little is known about the transport of the cuticular components to the plant surface. Various lines of evidence indicate that cuticular formation in Arabidopsis requires vesicular trafficking [14,15,52,70,71]. Although the related compositions of the vesicles are not well known, they may contain cutin precursors and/or proteins specifically involved in the transport of cuticular-related components to the cell surface. Previous reports have discovered that the trafficking of the intracellular wax components required a GNL1 (gnom like1-1) and ECH (echidna) dependent vesicle trafficking system [15]. It was reported that gnl1-1 and ech mutants of Arabidopsis were defective in protein secretions and wax accumulations on the plant surface. GNL1(At5g39500) encodes an ARF-GEF required for ER morphology and vesicle formation from the Golgi apparatus to the ER. Related results also showed that the wax-related components to the plasma membrane requires GNL1-dependent Golgi vesicle trafficking system. Here, our studies firstly demonstrate that AtMIN7, a key component of the vesicle trafficking system and an important immunity-associated protein, is required for the cutin-related component export to the cuticle layer for the related function. The atmin 7 mutant was defective in cuticle formation and the content of the total and several cutin monomer species were significantly reduced in the leaves of the atmin 7 mutant plants compared to WT. However, the wax load did not show significant differences in atmin 7 mutant plants compared to WT plants. Taken together, AtMIN7 might be specifically involved in the export of cutin building blocks or/and key enzymes involved in cutin formation through the intracellular trafficking system.

It is intriguing to find that groups of genes related with lipid transfer proteins (LTPs) and ABC transporters were significantly downregulated in atmin 7 mutant compared to WT plants based on the transcriptome analysis (Supplemental Table S1). Moreover, the hypothetical genes involved in cutin 
biosynthesis, such as the genes encoding GPATs and GDSL-lipases, were significantly downregulated in atmin 7 mutant compared to WT plants (Table S2). All these indicate that a mutation in AtMIN7 might not only directly affect the transport of cutin precursors, but also indirectly regulate the expression of proteins and enzymes involved in the deposition of cuticle-related components to the extracellular space.

\subsection{The Roles of Plant Cuticle During Plant-Pathogen Interaction}

The cuticle provides the first line of defense between the plant and its environment. It is becoming increasingly clear that the plant cuticle is an important player in plant-pathogen interactions [7]. Certain cutin monomers or wax components released from the permeable cuticle might be the signals to activate defense responses, or the permeable cuticle could release the defense elicitors from plant hosts, which could activate the faster and stronger plant defense responses [7]. For instance, LACS2 of the Arabidopsis plants encodes the long-chain Acyl-CoA synthetase 2. A mutation in LACS2 resulted in the defective cuticle formation [8]. Researchers found that lacs2 mutant showed significantly higher resistance against the fungal pathogen Botrytis cinerea, which might be due to the induction of the antifungal compounds in the defective cuticle [8]. However, the lacs2 mutant was more susceptible to Pto, indicating that the cuticle distinctly regulates defense against specific pathogens with discrete lifestyles and virulence strategies.

Here, we showed that the atmin 7 plants were more susceptible to the bacterial pathogen Pto when plants were infected by spray, but not infiltration. Pto proliferates significantly and causes disease following entry into the plant apoplast through natural openings, such as stomata and wounds [45]. In addition to leaf surfaces, cutin also forms a ledge on guard cells of stomata that supports their proper structure and function $[43,44]$. The atmin 7 mutant plants exhibited impaired stomata and defective stomata cuticular ledge. The differences of bacterial population of the atmin 7 mutant by applying spray and infiltration inoculation assays is consistent with the hypothesis that the impaired stomata cuticular ledge might impair the stomatal-based defense against bacterial entry.

\subsection{Plant Hormones Are Involved in Cuticle Formation and Cuticle-Mediated Defense Response}

Genetic and environmental factors could influence the cuticle quantities and compositions, which suggests that there is an actively regulated process for the cuticle formation [7]. For instance, it was reported that drought stress could enhance the cuticle formation [2]. Additionally, plant hormones play roles in cuticle formation and related functions. For instance, the exogenous application of $\mathrm{GA}_{7}$ increases the levels of cuticular lipid compounds and restores the systemic acquired resistance (SAR) in gl1 mutant plants [72]. Methyl-JA treatment of Vicia sativa seedlings increases the CYP94A1 transcript levels, which is involved in cutin monomer, w-hydroxy fatty acids (FAs) production [50]. Furthermore, the w-hydroxy FAs could induce the barley resistance against fungal pathogen Erysiphe graminis f. sp. [73]. ABA plays a positive role in cuticle formation in several plant species to protect plants from water loss during drought stress. A tomato mutation in ABA-deficient sitiens (SIT) - that is, deficient in ABA production-has a permeable cuticle and increases resistance against $B$. cinerea $[48,74]$. However, the exact interactions and integrations among the hormones, cuticle, and plant interaction with microbes are still unraveled.

In our study, it was discovered that a mutation in AtMIN7 led to the reduced levels of hormones, including SA, JA, and ABA. Thus, the AtMIN7-dependent vesicle trafficking system might also be associated with the components involved in hormone biosynthesis. Based on our results, these three hormones could specifically rescue the cuticle formation in the leaves of the atmin 7 mutant and restore the surface defense against Pto. A possible explanation for these effects of atmin7 could be that AtMIN7 plays a critical role in the interplay between plant hormones and plant cuticle formation for the related defense function against Pto DC3000.

In summary, we have discovered that an important vesicle trafficking component, AtMIN7, is involved in cuticle formation, potentially by affecting the transport of cutin precursors 
and/or cutin biosynthesis-related proteins and enzymes. Notably, these defects correlate with related defense against leaf surface infection with Pto. Our model of the mechanism of AtMIN7 activity in cuticle formation is shown in Figure 8. Our study also demonstrates the potential capacity of AtMIN7 to affect hormone biosynthesis and to integrate the response to hormones with modification of the cuticle for defense against Pto DC3000. Further investigation of the mechanisms and related networks of AtMIN7 may enable strategies to enhance plant health and yield through the genetic manipulation of plant cuticle, which will reduce the agricultural chemical applications to benefit the environment and human health.

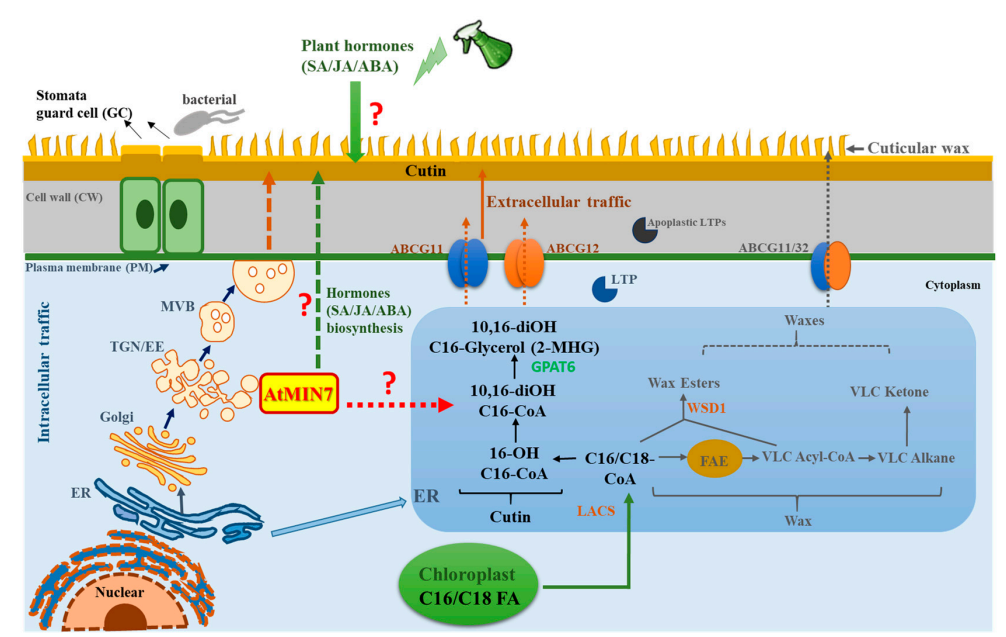

Figure 8. Hypothetical model representing the role of AtMIN7 involved in the cuticle formation and cuticle-associated defense response. The fatty acyl groups (C16/C18 FAs) are generated in the plastid, which are exported from the plastid to the ER as C16/C18-CoA. In the ER, C16/C18-CoA are synthesized as wax and cutin precursors $[1,67]$. The intracellular transport pathway for wax- and cutin-related components from the ER to the plasma membrane (PM) are predicted by several putative mechanisms, one of which is the Golgi or TGN-mediated secretory pathway [1,13-15]. Multivesicular bodies (MVBs) are the late endosomes in plants, which can form intraluminal vesicles involved in the delivery of defense cargoes upon the pathogen infection $[75,76]$. Here, MVBs might be involved in the intracellular transport of the wax- and cutin-related components. The extracellular export of the wax- and cutin-related components across the PM and cell wall of Arabidopsis is predicted to be carried out by the ATP-binding cassette (ABC) transporters and lipid transfer proteins (LTPs) [13,17,52]. However, very limited knowledge was known for the detailed mechanisms. TGN/EE serves as a key sorting station at the intersection of secretory and endocytic pathways [27]. ARF-GEF proteins play a critical role in vesicle budding and vesicular protein sorting [39,40]. In the present study, the TGN/EE-localized AtMIN7, an Arabidopsis ARF-GEF, is discovered to be critical for the cutin formation, which may play important roles in the sorting, assembling, or delivering cutin precursors or other related important components, such as the proteins and enzymes, involved in cutin formation through the intracellular trafficking pathway. Moreover, AtMIN7 might be involved in hormones (SA, JA, and ABA) biosynthesis, and also might be associated with the integration between plant hormones (specifically for SA, JA, and ABA) and plant cuticle for the defense against the Pto DC3000 pathogen infection in Arabidopsis plants. The detailed mechanisms are not well known, which need to be further investigated. FAE: fatty acid elongase; ABCG: ATP-binding cassette (ABC) transporter; LTP: lipid transfer protein; LACS: long-chain acyl-CoA synthetase; ER: endoplasmic reticulum; PM: plasma membrane; TGN/EE: trans-Golgi network/early endosome; MVB: multivesicular body. Solid arrows represent the well-studied mechanisms and pathways currently known. Question marks and dotted arrows indicate the unknown or hypothetical mechanisms and pathways. 


\section{Materials and Methods}

\subsection{Plant Materials and the Homozygous Line Identification}

The seeds of wild-type (WT) Columbia (Col-0) Arabidopsis and the atmin7 mutant line (Salk_013761) were used in this study, which were obtained from the Arabidopsis Biological Resource Center (http://www.arabidopsis.org/). The WT and mutant plants were grown in pots with a commercialized potting mixture in a growth room with the environmental conditions of $60 \%$ humidity, $22{ }^{\circ} \mathrm{C}$, 10-h light/14-h darkness photoperiod [77]. The growth condition is also applied for the phenotype observation and pathogen inoculation. The protocol from the Salk Institute Genomic Analysis Laboratory (http://signal.salk.edu/tdnaprimers.2.html) was used to identify the atmin 7 homozygous lines. The homozygous line was identified by the PCR using the primers of the atmin7 LP and RP, and LBb1.3, which are listed in Supplemental Table S3. The PCR products were analyzed on the agarose gels. The seeds of complementation line of atmin7 (35S::MIN7-GFP) were kindly provided by Dr. Shengyang He [36].

\subsection{Phylogenetic Tree Construction}

Protein sequences of all eight ARF-GEF isoforms were used for multiple protein sequence alignments via Clustal Omega software and for the further phylogenetic analysis (https://www.ebi.ac. uk/Tools/msa/clustalo/). The phylogenetic tree was obtained from Simple Phylogeny via EMBL-EBI. The phylogenetic tree was constructed based on the alignment with the default parameters and displayed in straight branches and cladogram.

\subsection{Chlorophyll Content Measurement}

The four-week-old plant leaves from each genotype were collected and weighted, which were then immersed in $30 \mathrm{~mL} 80 \%$ ethanol in the glass tube at the room temperature. The glass tubes were wrapped in the foil to avoid light exposure. $1 \mathrm{~mL}$ of the supernatant was removed at $30 \mathrm{~min}$ intervals (up to $120 \mathrm{~min}$ ) after the immersion. A spectrometer (Thermo scientific Genesys 10S VIS Spectrophotometer, Thermo Scientific ${ }^{\mathrm{TM}}$, Columbus, OH, USA) was used for the chlorophyll content measurement with the absorbance at 664 and $647 \mathrm{~nm}$. The micromolar concentration of total chlorophyll per gram of fresh weight of leaf tissues was calculated by the equation: Total micromoles chlorophyll = 7.93(A664) +19.53(A647) [42].

\subsection{Plant Hormone Treatments}

Hormone treatments were conducted by spraying SA $(1 \mathrm{mM}), \mathrm{JA}(50 \mu \mathrm{M}), \mathrm{ABA}(50 \mu \mathrm{M})$, gibberellic acid $\left(\mathrm{GA}_{3}, 100 \mu \mathrm{M}\right)$, and indole-3-acetic acid (IAA,10 $\left.\mu \mathrm{M}\right)$ solutions to the Arabidopsis plant leaves until there was imminent runoff, which indicated that the leaf surfaces were well covered with the hormone solution (generally, $5 \mathrm{~mL}$ solution for each plant). For hormone treatment solution preparation, 100\% EtOH $(500 \mu \mathrm{L})$ was firstly used to dissolve SA, JA, and ABA, which were further diluted in $1 \mathrm{~L}$ distilled and deionized water to reach the final treatment concentration, respectively. Accordingly, $1 \mathrm{~L}$ distilled and deionized water with $500 \mu \mathrm{L} 100 \% \mathrm{EtOH}$ was sprayed as the control [72,78-80]. During the spray process, a spray bottle with a nozzle set was used to spray a very fine mist $[72,81]$. $24 \mathrm{~h}$ after the hormone treatments, the plant leaves were subjected to the further tests including the staining with TB or surface inoculation with Pto DC3000.

\subsection{Pathogen Culture Condition and Bacterial Growth Assays}

In this study, the Pto DC3000 cells were grown on the King's B plate with rifampin as the selective antibiotic. The fresh bacterial cells grown on plates were collected and diluted in $10 \mathrm{mM} \mathrm{MgCl}_{2}$. For the pathogen inoculation assay, bacterial broth with the concentration of $1 \times 10^{5} \mathrm{CFU}$ (colony forming unit)/mL (OD600 = 0.0002) in $10 \mathrm{mM} \mathrm{MgCl}_{2}$ were infiltrated into the abaxial side of the 
four-week-old Arabidopsis leaves using the $1 \mathrm{~mL}$ syringe. The residues were wiped off from the leaves after infiltration. The inoculated plants were left for one hour and then returned to the growth room. The bacterial growth was determined three days after the inoculation [9]. Three leaf discs for each technical replicate were collected. For each treatment, six technical replicates were applied. The bacterial titer was determined by grinding leaf discs thoroughly in $10 \mathrm{mM} \mathrm{MgCl} 2$ with a serial of dilution. The final diluted solution was plated onto the King's B plates with rifampin. Colonies were counted and used to calculate the mean $\mathrm{CFU} / \mathrm{cm}^{2}$ for each treatment, and the final values were log transformed. Each biological replicate was calculated as a single data point. Multiple independent biological replicates were used to calculate the mean, SD, and significant differences.

\subsection{Cuticular Wax and Cutin Content Analysis}

The cuticular wax and cutin monomer contents of leaves from four-week-old plants were determined as described by Lü and Yang et al. [2,82,83]. For wax extraction, four-week-old Arabidopsis rosette leaves from each genotype were weighted and extended gently for the area measurement. The collected leaves were submerged in $20 \mathrm{~mL}$ hexane twice for $30 \mathrm{~s}$. The solutions were mixed into a clean vial for the total cuticular extraction. $50 \mu \mathrm{L}$ internal standard (ISTD, N-Hexadecane, ICN Bio-medicals Inc., concentration $5 \mu \mathrm{g} / 50 \mu \mathrm{L}$ ) was added into the vials by a micropipette. After the addition of ISTD, the samples were dried up under the evaporating unit $\left(\mathrm{N}^{2}\right.$ gas). Then, the samples were derivatized with $50 \mu \mathrm{L}$ of BSTFA (N,O-Bis(trimethylsilyl)trifluoroacetamide) and immediately placed in a $100{ }^{\circ} \mathrm{C}$ dry bath for $15 \mathrm{~min} .200 \mu \mathrm{L}$ hexane was added into each sample to dissolve the wax extracts. Agilent 7820A gas chromatograph equipped with a flame ionization detector, together with a 30-m, 0.25-mm DB-5 capillary column with helium as the carrier gas, were used for GC analysis. The column temperature was programmed as following: an initial temperature of $80^{\circ} \mathrm{C}$ for two minutes, increased to $200{ }^{\circ} \mathrm{C}\left(40{ }^{\circ} \mathrm{C} \mathrm{min}-1\right)$ and held for two minutes, then increased to $270{ }^{\circ} \mathrm{C}\left(10^{\circ} \mathrm{C}\right.$ $\left.\mathrm{min}^{-1}\right)$ and held for two minutes, and finally increased to $320^{\circ} \mathrm{C}\left(3^{\circ} \mathrm{C} \mathrm{min}^{-1}\right)$ and held for $40 \mathrm{~min}$. The flame ionization detector (FID) peak areas relative to the internal standard n-Hexadecane was applied to quantify the samples. An Agilent 7890A gas chromatograph equipped with an Agilent 5975C mass spectrometric detector was applied to determine the individual wax species $(70 \mathrm{eV}$; mass-to-charge ratio of 50-750) [82].

The left plant leaf samples used for the wax extraction were applied for the further cutin monomer extraction, which were immersed in $15 \mathrm{~mL}$ isopropanol in an $85^{\circ} \mathrm{C}$ incubator for $10-15 \mathrm{~min}$, and then placed on a shaker with stirring for two hours. Furthermore, the samples were delipidated deeply with isopropanol, chloroform/methanol $(2: 1, v / v)$, chloroform/methanol $(1: 2, v / v)$, and methanol for one day. Finally, the tubes with samples were centrifuged for $10 \mathrm{~min}$ at $2000 \mathrm{rpm}$. The solvent was removed from each tube. The residues in the tubes were dried up under the hood for three to five days until the constant weight was reached. Next, the dried samples were weighed and undergone depolymerization, which is the methanolysis process with sodium methoxide. $25 \mathrm{mg}$ methyl heptadecanoate and $25 \mathrm{mg}$ $\omega$-pentadecalactone were applied as internal standards. Samples with internal standards, $0.9 \mathrm{~mL}$ methyl acetate, $1.5 \mathrm{~mL}$ sodium methoxide, and $3.6 \mathrm{~mL}$ methanol were heated at $60^{\circ} \mathrm{C}$ for two hours. After cooling down, $10 \mathrm{~mL}$ methylene dichloride and $0.5 \mathrm{~mL}$ glacial acetic acid were used for fatty acid methyl esters extraction. After this step, the extracts were washed with $0.5 \mathrm{M} \mathrm{NaCl}$ for three times, and then dried up under $\mathrm{N}^{2}$ gas. For the further derivatization, the hydroxyl groups were acetylated by $200 \mu \mathrm{L}$ pyridine/acetic anhydride $(1: 1, v / v)$ at $60^{\circ} \mathrm{C}$ for one hour, to produce the corresponding acetyl derivatives. The extracts were evaporated under $\mathrm{N}^{2}$ gas, and dissolved in chloroform, which were ready for GC-MS analysis. Agilent 7820A gas chromatograph equipped with a flame ionization detector, together with a 30-m, 0.25-mm DB-5 capillary column with helium as the carrier gas, were used for the sample analysis. The column temperature was programmed as following: an initial temperature of $80^{\circ} \mathrm{C}$ increased to $200{ }^{\circ} \mathrm{C}\left(15^{\circ} \mathrm{C} \mathrm{min}-1\right)$, then increased to $230{ }^{\circ} \mathrm{C}\left(2{ }^{\circ} \mathrm{C} \mathrm{min}-1\right)$, held for $10 \mathrm{~min}$. The FID peak areas relative to the internal standard methyl heptadecanoate and $\omega$-pentadecalactone were applied to quantify the samples. The individual cutin monomers were measured with an Agilent 
7890A gas chromatograph equipped with an Agilent 5975C mass spectrometric detector $(70 \mathrm{eV}$; mass-to-charge ratio of 50-750) [2,82].

\subsection{SEM and TEM}

Hitachi H-7500 TEM equipped with the SIA-L12C digital camera was used to observe the cuticle layer of the leaves and cuticular ledge of stomata. Hitachi Schottky field emission SU5000 SEM equipped with the Bruker Energy Dispersive X-ray Spectrometer ESPRIT system for the qualitative and quantitative elemental microanalysis was used to observe the leaf surface, leaf section, and stomata structure. Leaf samples were collected from plants at four weeks of growth. Samples were prepared and observed at the Molecular \& Cellular Imaging Center (MCIC) at The Ohio State University as previously reported $[84,85]$.

\subsection{Hormone Level Determination}

The methods of hormone SA, JA, and ABA extraction and detection were modified from the papers published by Forcat et al (2008) [86] The leaves from four-week-old Arabidopsis plants (approximately $110 \mathrm{mg}$ fresh weight per sample) were collected with $400 \mu \mathrm{L}$ extraction buffer containing $10 \%$ methanol and $1 \%$ acetic acid. The isotope labelled internal standards $\left(\mathrm{d}_{4}-\mathrm{SA}, \mathrm{d}_{5}-\mathrm{JA}\right.$, and $\left.\mathrm{d}_{6}-\mathrm{ABA}\right)$ were added at the beginning of the extraction. The amounts of the internal standards were $15 \mathrm{ng}{ }^{2} \mathrm{H} 4-\mathrm{SA}\left(\mathrm{d}_{4}-\mathrm{SA}\right.$, CDN Isotopes, Pointe-Claire, QC, Canada, part \#: D-1156) and 150 ng ${ }^{2} \mathrm{H} 5-J A$ (d $\mathrm{d}_{5}-\mathrm{JA}, \mathrm{CDN}$ Isotopes, Pointe-Claire, QC, Canada, part \#D-6936), and $1 \mathrm{ng}$ of ${ }^{2} \mathrm{H6}$-ABA ( $\mathrm{d}_{6}$-ABA, Toronto Research Chemicals, North York, ON, USA; part \#: A110002). After the addition of the extraction buffer, the tubes with extracts were incubated on ice for $30 \mathrm{~min}$, and then centrifuged at $4{ }^{\circ} \mathrm{C}(13,000 \times g, 10 \mathrm{~min})$. The supernatant was collected into new tubes. The left pellets were re-extracted with $400 \mu \mathrm{L}$ extraction buffer without adding the internal standard. The tubes with extracts were centrifuged again. The two supernatant solutions were mixed for further analysis through UPLC/ESI/MS by the Thermal Fisher Ultimate 3000 system (Thermal Fisher, Waltham, MA, USA) with a $3 \mu \mathrm{m} \mathrm{C18}(100 \mathrm{~mm} \times 2.0 \mathrm{~mm})$ column (Waters Company, Milford, MA, USA) at $35^{\circ} \mathrm{C}$. The mobile phase was set for a continuum gradient from $\left(94.9 \% \mathrm{H}_{2} \mathrm{O}: 5 \% \mathrm{CH}_{3} \mathrm{CN}: 0.1 \% \mathrm{CHOOH}\right)$ to $\left(5 \% \mathrm{H}_{2} \mathrm{O}: 94.9 \% \mathrm{CH}_{3} \mathrm{CN}: 0.1 \% \mathrm{CHOOH}\right)$ for about $20 \mathrm{~min}$. Multiple reaction monitoring (MRM) of ion pairs for the labelled and endogenous hormones were used for the analysis of the compounds. The retention time and mass transitions for $\mathrm{SA}, \mathrm{JA}$, and $\mathrm{ABA}$ were verified based on the authentic standards. The daughter masses were indicated in the brackets listed below. The transition settings for SA, JA, and ABA: ${ }^{2} \mathrm{H}_{4}$-SA 141 (97), SA 137 (93), SA-Gly 299 (93), ${ }^{2} \mathrm{H}_{5}$-JA 214 (61), JA 209 (59), JA-Ile/Leu 322 (130), ${ }^{2} \mathrm{H}_{6}$-ABA 269 (159), and ABA 263 (153).

\subsection{RNA-Seq Data Analysis}

The total RNA was extracted from the leaves of four-week old WT Col-0 and min7 mutant plants using TRIzol Reagent (Invitrogen, Carlsbad, MA, USA) following the manufacturer's instructions. Total RNA was quantified and checked using a Nanodrop-ND 8000 spectrophotometer (Thermo Fisher Scientific, Columbus, OH, USA). Replicated samples with the RNA integrity number of 7.5 and above were chosen for the further analysis. The RNA-Seq was further carried out with an Illumina HiSeq4000 PE150 at Novogene Bioinformatics Technology Co., Ltd. (Beijing, China). The clean data were mapped to the Tair10 genome release files using TopHat2 (mismatch $=2$ ). The read numbers mapped to each gene were counted using HTSeq (-m union) and the reads count was used to calculate the FPKM (expected number of fragments per kilobase of transcript sequence per million base pairs sequenced) [87]. The DEGSeq R package $(q<0.005$ and $\log 2$ (fold change) $>2$ ) was used for the differential gene expression analysis. The $p$-values were adjusted with the Benjamini and Hochberg method. 
Supplementary Materials: Supplementary materials can be found at http:/www.mdpi.com/1422-0067/21/15/ 5547/s1.

Author Contributions: Conceptualization, Z.Z., D.M., and Y.X.; methodology, Z.Z., X.Y., and S.L.; software, S.O.; formal analysis, Z.Z.; investigation, Z.Z., X.Y., J.F., P.Y., and J.M.; data curation, Z.Z. and S.O.; writing-original draft preparation, Z.Z.; writing - review and editing, Z.Z., S.L., D.M., and Y.X.; visualization, Z.Z.; supervision, Z.Z., D.M., and Y.X.; project administration, Z.Z. and Y.X.; and funding acquisition, D.M. and Y.X. All authors have read and agreed to the published version of the manuscript.

Funding: This research was funded by the Hatch Project from USDA-NIFA, grant number USDA-NIFA-OHO01392 to Y.X.; the Ohio Agricultural Research and Development Center (OARDC) seed grant OHOA1591 to Y.X. and D.M.; and startup funds from OARDC and The Ohio State University to Y.X.

Acknowledgments: We thank the Arabidopsis Biological Resource Center for providing the Arabidopsis seeds and constructs, and Shengyang He for providing us with the atmin 7 complementation line. We are grateful to Tea Meulia from the Molecular and Cellular Imaging Center at OSU for her help with TEM and SEM and to Mathew Bernier from the Mass Spectrometry and Proteomics Facility at OSU for his help with hormone level analyses.

Conflicts of Interest: The authors declare no conflict of interest.

\section{References}

1. Bernard, A.; Joubes, J. Arabidopsis cuticular waxes: Advances in synthesis, export and regulation. Prog. Lipid Res. 2013, 52, 110-129. [CrossRef] [PubMed]

2. Lu, S.; Zhao, H.; Des Marais, D.L.; Parsons, E.P.; Wen, X.; Xu, X.; Bangarusamy, D.K.; Wang, G.; Rowland, O.; Juenger, T.; et al. Arabidopsis ECERIFERUM9 involvement in cuticle formation and maintenance of plant water status. Plant Physiol. 2012, 159, 930-944. [CrossRef] [PubMed]

3. Yeats, T.H.; Rose, J.K. The formation and function of plant cuticles. Plant Physiol. 2013, 163, 5-20. [CrossRef]

4. Kim, H.; Tai, T.H. Identifying a Candidate Mutation Underlying a Reduced Cuticle Wax Mutant of Rice Using Targeted Exon Capture and Sequencing. Plant Breed. Biotechnol. 2019, 7, 1-11. [CrossRef]

5. Tafolla-Arellano, J.C.; Báez-Sañudo, R.; Tiznado-Hernández, M.E. The cuticle as a key factor in the quality of horticultural crops. Sci. Hortic. 2018, 232, 145-152. [CrossRef]

6. Rutter, B.D.; Innes, R.W. Extracellular vesicles as key mediators of plant-microbe interactions. Curr. Opin. Plant Biol. 2018, 44, 16-22. [CrossRef]

7. Ziv, C.; Zhao, Z.; Gao, Y.G.; Xia, Y. Multifunctional Roles of Plant Cuticle During Plant-Pathogen Interactions. Front. Plant Sci. 2018, 9, 1088. [CrossRef]

8. Tang, S.; Chen, N.; Song, B.; He, J.; Zhou, Y.; Jenks, M.A.; Xu, X. Compositional and transcriptomic analysis associated with cuticle lipid production on rosette and inflorescence stem leaves in the extremophyte Thellungiella salsuginea. Physiol. Plant 2019, 165, 584-603. [CrossRef]

9. Xia, Y.; Gao, Q.M.; Yu, K.; Lapchyk, L.; Navarre, D.; Hildebrand, D.; Kachroo, A.; Kachroo, P. An intact cuticle in distal tissues is essential for the induction of systemic acquired resistance in plants. Cell Host Microbe. 2009, 5, 151-165. [CrossRef]

10. Lee, S.B.; Suh, M.C. Recent advances in cuticular wax biosynthesis and its regulation in Arabidopsis. Mol. Plant 2013, 6, 246-249. [CrossRef]

11. Lee, S.B.; Suh, M.C. Advances in the understanding of cuticular waxes in Arabidopsis thaliana and crop species. Plant Cell. Rep. 2015, 34, 557-572. [CrossRef] [PubMed]

12. Bourgault, R.; Matschi, S.; Vasquez, M.; Qiao, P.; Sonntag, A.; Charlebois, C.; Mohammadi, M.; Scanlon, M.J.; Smith, L.G.; Molina, I. Constructing functional cuticles: Analysis of relationships between cuticle lipid composition, ultrastructure and water barrier function in developing adult maize leaves. Ann. Bot. 2020, 125, 79-91. [CrossRef] [PubMed]

13. Li, N.; Xu, C.; Li-Beisson, Y.; Philippar, K. Fatty Acid and Lipid Transport in Plant Cells. Trends Plant Sci. 2016, 21, 145-158. [CrossRef]

14. Dominguez, E.; Heredia-Guerrero, J.A.; Heredia, A. Plant cutin genesis: Unanswered questions. Trends Plant Sci. 2015, 20, 551-558. [CrossRef] [PubMed]

15. McFarlane, H.E.; Watanabe, Y.; Yang, W.; Huang, Y.; Ohlrogge, J.; Samuels, A.L. Golgi- and trans-Golgi network-mediated vesicle trafficking is required for wax secretion from epidermal cells. Plant Physiol. 2014, 164, 1250-1260. [CrossRef] [PubMed] 
16. Xia, Y.; Yu, K.; Gao, Q.M.; Wilson, E.V.; Navarre, D.; Kachroo, P.; Kachroo, A. Acyl CoA Binding Proteins are Required for Cuticle Formation and Plant Responses to Microbes. Front. Plant Sci. 2012, 3, 224. [CrossRef]

17. Fich, E.A.; Segerson, N.A.; Rose, J.K. The Plant Polyester Cutin: Biosynthesis, Structure, and Biological Roles. Annu. Rev. Plant Biol. 2016, 67, 207-233. [CrossRef]

18. Pighin, J.A.; Zheng, H.; Balakshin, L.J.; Goodman, I.P.; Western, T.L.; Jetter, R.; Kunst, L.; Samuels, A.L. Plant cuticular lipid export requires an ABC transporter. Science 2004, 306, 702-704. [CrossRef]

19. McFarlane, H.E.; Shin, J.J.; Bird, D.A.; Samuels, A.L. Arabidopsis ABCG transporters, which are required for export of diverse cuticular lipids, dimerize in different combinations. Plant Cell 2010, 22, 3066-3075. [CrossRef]

20. Panikashvili, D.; Aharoni, A. ABC-type transporters and cuticle assembly: Linking function to polarity in epidermis cells. Plant Signal. Behav. 2008, 3, 806-809. [CrossRef]

21. Panikashvili, D.; Shi, J.X.; Schreiber, L.; Aharoni, A. The Arabidopsis ABCG13 transporter is required for flower cuticle secretion and patterning of the petal epidermis. New Phytol. 2011, 190, 113-124. [CrossRef] [PubMed]

22. Kim, H.; Lee, S.B.; Kim, H.J.; Min, M.K.; Hwang, I.; Suh, M.C. Characterization of glycosylphosphatidylinositol-anchored lipid transfer protein 2 (LTPG2) and overlapping function between LTPG/LTPG1 and LTPG2 in cuticular wax export or accumulation in Arabidopsis thaliana. Plant Cell Physiol. 2012, 53, 1391-1403. [CrossRef] [PubMed]

23. Rosquete, M.R.; Davis, D.J.; Drakakaki, G. The Plant Trans-Golgi Network: Not Just a Matter of Distinction. Plant Physiol. 2018, 176, 187-198. [CrossRef] [PubMed]

24. Gu, Y.; Zavaliev, R.; Dong, X. Membrane Trafficking in Plant Immunity. Mol. Plant 2017, 10, 1026-1034. [CrossRef] [PubMed]

25. Monaghan, J.; Zipfel, C. Plant pattern recognition receptor complexes at the plasma membrane. Curr. Opin. Plant Biol. 2012, 15, 349-357. [CrossRef] [PubMed]

26. Robatzek, S. Vesicle trafficking in plant immune responses. Cell Microbiol. 2007, 9, 1-8. [CrossRef]

27. Rosquete, M.R.; Drakakaki, G. Plant TGN in the stress response: A compartmentalized overview. Curr. Opin. Plant Biol. 2018, 46, 122-129. [CrossRef]

28. Paez Valencia, J.; Goodman, K.; Otegui, M.S. Endocytosis and Endosomal Trafficking in Plants. Annu. Rev. Plant Biol. 2016, 67, 309-335. [CrossRef]

29. LaMontagne, E.D.; Heese, A. Trans-Golgi network/early endosome: A central sorting station for cargo proteins in plant immunity. Curr. Opin. Plant Biol. 2017, 40, 114-121. [CrossRef]

30. Gu, Y.; Innes, R.W. The KEEP ON GOING protein of Arabidopsis recruits the ENHANCED DISEASE RESISTANCE1 protein to trans-Golgi network/early endosome vesicles. Plant Physiol. 2011, 155, 1827-1838. [CrossRef]

31. Wang, W.; Wen, Y.; Berkey, R.; Xiao, S. Specific targeting of the Arabidopsis resistance protein RPW8.2 to the interfacial membrane encasing the fungal Haustorium renders broad-spectrum resistance to powdery mildew. Plant Cell 2009, 21, 2898-2913. [CrossRef] [PubMed]

32. Ekanayake, G.; LaMontagne, E.D.; Heese, A. Never Walk Alone: Clathrin-Coated Vesicle (CCV) Components in Plant Immunity. Annu. Rev. Phytopathol. 2019, 57, 387-409. [CrossRef] [PubMed]

33. D'Souza-Schorey, C.; Chavrier, P. ARF proteins: Roles in membrane traffic and beyond. Nat. Rev. Mol. Cell Biol. 2006, 7, 347-358. [CrossRef] [PubMed]

34. Teh, O.K.; Moore, I. An ARF-GEF acting at the Golgi and in selective endocytosis in polarized plant cells. Nature 2007, 448, 493-496. [CrossRef] [PubMed]

35. Nomura, K.; DebRoy, S.; Lee, Y.H.; Pumplin, N.; Jones, J.; He, S.Y. A bacterial virulence protein suppresses host innate immunity to cause plant disease. Science 2006, 313, 220-223. [CrossRef]

36. Nomura, K.; Mecey, C.; Lee, Y.N.; Imboden, L.A.; Chang, J.H.; He, S.Y. Effector-triggered immunity blocks pathogen degradation of an immunity-associated vesicle traffic regulator in Arabidopsis. Proc. Natl. Acad. Sci. USA 2011, 108, 10774-10779. [CrossRef]

37. Tanaka, H.; Kitakura, S.; De Rycke, R.; De Groodt, R.; Friml, J. Fluorescence imaging-based screen identifies ARF GEF component of early endosomal trafficking. Curr. Biol. 2009, 19, 391-397. [CrossRef]

38. Tanaka, H.; Kitakura, S.; Rakusova, H.; Uemura, T.; Feraru, M.I.; De Rycke, R.; Robert, S.; Kakimoto, T.; Friml, J. Cell polarity and patterning by PIN trafficking through early endosomal compartments in Arabidopsis thaliana. PLoS Genet. 2013, 9, e1003540. [CrossRef] 
39. Kitakura, S.; Adamowski, M.; Matsuura, Y.; Santuari, L.; Kouno, H.; Arima, K.; Hardtke, C.S.; Friml, J.; Kakimoto, T.; Tanaka, H. BEN3/BIG2 ARF GEF is Involved in Brefeldin A-Sensitive Trafficking at the trans-Golgi Network/Early Endosome in Arabidopsis thaliana. Plant Cell Physiol. 2017, 58, 1801-1811. [CrossRef]

40. Kania, U.; Nodzynski, T.; Lu, Q.; Hicks, G.R.; Nerinckx, W.; Mishev, K.; Peurois, F.; Cherfils, J.; De Rycke, R.; Grones, P.; et al. The Inhibitor Endosidin 4 Targets SEC7 Domain-Type ARF GTPase Exchange Factors and Interferes with Subcellular Trafficking in Eukaryotes. Plant Cell 2018, 30, 2553-2572. [CrossRef]

41. Tanaka, T.; Tanaka, H.; Machida, C.; Watanabe, M.; Machida, Y. A new method for rapid visualization of defects in leaf cuticle reveals five intrinsic patterns of surface defects in Arabidopsis. Plant J. 2004, 37, 139-146. [CrossRef] [PubMed]

42. Lolle, S.J.; Berlyn, G.P.; Engstrom, E.M.; Krolikowski, K.A.; Reiter, W.-D.; Pruitt, R.E. Developmental Regulation of Cell Interactions in theArabidopsis fiddlehead-1Mutant: A Role for the Epidermal Cell Wall and Cuticle. Dev. Biol. 1997, 189, 311-321. [CrossRef] [PubMed]

43. Li, Y.; Beisson, F.; Koo, A.J.; Molina, I.; Pollard, M.; Ohlrogge, J. Identification of acyltransferases required for cutin biosynthesis and production of cutin with suberin-like monomers. Proc. Natl. Acad. Sci. USA 2007, 104, 18339-18344. [CrossRef] [PubMed]

44. Tang, J.; Yang, X.; Xiao, C.; Li, J.; Chen, Y.; Li, R.; Li, S.; Lü, S.; Hu, H. GDSL lipase Occluded Stomatal Pore 1 is required for wax biosynthesis and stomatal cuticular ledge formation. New Phytol. 2020. [CrossRef]

45. Xin, X.F.; He, S.Y. Pseudomonas syringae pv. tomato DC3000: A model pathogen for probing disease susceptibility and hormone signaling in plants. Annu. Rev. Phytopathol. 2013, 51, 473-498. [CrossRef]

46. Pieterse, C.M.; Leon-Reyes, A.; Van der Ent, S.; Van Wees, S.C. Networking by small-molecule hormones in plant immunity. Nat. Chem. Biol. 2009, 5, 308-316. [CrossRef]

47. Robert-Seilaniantz, A.; Navarro, L.; Bari, R.; Jones, J.D. Pathological hormone imbalances. Curr. Opin. Plant Biol. 2007, 10, 372-379. [CrossRef]

48. Cui, F.; Wu, W.; Wang, K.; Zhang, Y.; Hu, Z.; Brosche, M.; Liu, S.; Overmyer, K. Cell death regulation but not abscisic acid signaling is required for enhanced immunity to Botrytis in Arabidopsis cuticle-permeable mutants. J. Exp. Bot. 2019, 70, 5971-5984. [CrossRef]

49. Macková, J.; Vašková, M.; Macek, P.; Hronková, M.; Schreiber, L.; Šantrůček, J. Plant response to drought stress simulated by ABA application: Changes in chemical composition of cuticular waxes. Environ. Exp. Bot. 2013, 86, 70-75. [CrossRef]

50. Pinot, F.; Benveniste, I.; Salaün, J.-P.; Durst, F. Methyl Jasmonate Induces Lauric Acid $\omega$-Hydroxylase Activity and Accumulation of CYP94A1 Transcripts but Does Not Affect Epoxide Hydrolase Activities inVicia sativaSeedlings. Plant Physiol. 1998, 118, 1481-1486. [CrossRef]

51. Anderson, J.P.; Badruzsaufari, E.; Schenk, P.M.; Manners, J.M.; Desmond, O.J.; Ehlert, C.; Maclean, D.J.; Ebert, P.R.; Kazan, K. Antagonistic interaction between abscisic acid and jasmonate-ethylene signaling pathways modulates defense gene expression and disease resistance in Arabidopsis. Plant Cell 2004, 16, 3460-3479. [CrossRef] [PubMed]

52. Bakan, B.; Marion, D. Assembly of the Cutin Polyester: From Cells to Extracellular Cell Walls. Plants (Basel) 2017, 6, 57. [CrossRef]

53. Beisson, F.; Li, Y.; Bonaventure, G.; Pollard, M.; Ohlrogge, J.B. The acyltransferase GPAT5 is required for the synthesis of suberin in seed coat and root of Arabidopsis. Plant Cell 2007, 19, 351-368. [CrossRef] [PubMed]

54. Petit, J.; Bres, C.; Mauxion, J.P.; Tai, F.W.; Martin, L.B.; Fich, E.A.; Joubes, J.; Rose, J.K.; Domergue, F.; Rothan, C. The Glycerol-3-Phosphate Acyltransferase GPAT6 from Tomato Plays a Central Role in Fruit Cutin Biosynthesis. Plant Physiol. 2016, 171, 894-913. [CrossRef] [PubMed]

55. Yang, W.; Pollard, M.; Li-Beisson, Y.; Beisson, F.; Feig, M.; Ohlrogge, J. A distinct type of glycerol-3-phosphate acyltransferase with sn-2 preference and phosphatase activity producing 2-monoacylglycerol. Proc. Natl. Acad. Sci. USA 2010, 107, 12040-12045. [CrossRef]

56. Girard, A.L.; Mounet, F.; Lemaire-Chamley, M.; Gaillard, C.; Elmorjani, K.; Vivancos, J.; Runavot, J.L.; Quemener, B.; Petit, J.; Germain, V.; et al. Tomato GDSL1 is required for cutin deposition in the fruit cuticle. Plant Cell 2012, 24, 3119-3134. [CrossRef]

57. Panikashvili, D.; Savaldi-Goldstein, S.; Mandel, T.; Yifhar, T.; Franke, R.B.; Hofer, R.; Schreiber, L.; Chory, J.; Aharoni, A. The Arabidopsis DESPERADO/AtWBC11 transporter is required for cutin and wax secretion. Plant Physiol. 2007, 145, 1345-1360. [CrossRef] 
58. Panikashvili, D.; Shi, J.X.; Bocobza, S.; Franke, R.B.; Schreiber, L.; Aharoni, A. The Arabidopsis DSO/ABCG11 transporter affects cutin metabolism in reproductive organs and suberin in roots. Mol. Plant 2010, 3, 563-575. [CrossRef]

59. Raffaele, S.; Vailleau, F.; Léger, A.; Joubès, J.; Miersch, O.; Huard, C.; Blée, E.; Mongrand, S.; Domergue, F.; Roby, D. A MYB transcription factor regulates very-long-chain fatty acid biosynthesis for activation of the hypersensitive cell death response in Arabidopsis. Plant Cell 2008, 20, 752-767. [CrossRef]

60. Lee, S.B.; Kim, H.U.; Suh, M.C. MYB94 and MYB96 Additively Activate Cuticular Wax Biosynthesis in Arabidopsis. Plant Cell Physiol. 2016, 57, 2300-2311. [CrossRef]

61. Zhang, Y.L.; Zhang, C.L.; Wang, G.L.; Wang, Y.X.; Qi, C.H.; Zhao, Q.; You, C.X.; Li, Y.Y.; Hao, Y.J. The R2R3 MYB transcription factor MdMYB30 modulates plant resistance against pathogens by regulating cuticular wax biosynthesis. BMC Plant Biol. 2019, 19, 362. [CrossRef] [PubMed]

62. Oshima, Y.; Shikata, M.; Koyama, T.; Ohtsubo, N.; Mitsuda, N.; Ohme-Takagi, M. MIXTA-like transcription factors and WAX INDUCER1/SHINE1 coordinately regulate cuticle development in Arabidopsis and Torenia fournieri. Plant Cell 2013, 25, 1609-1624. [CrossRef]

63. Seo, P.J.; Lee, S.B.; Suh, M.C.; Park, M.J.; Go, Y.S.; Park, C.M. The MYB96 transcription factor regulates cuticular wax biosynthesis under drought conditions in Arabidopsis. Plant Cell 2011, 23, 1138-1152. [CrossRef] [PubMed]

64. Cominelli, E.; Sala, T.; Calvi, D.; Gusmaroli, G.; Tonelli, C. Over-expression of the Arabidopsis AtMYB41 gene alters cell expansion and leaf surface permeability. Plant J. 2008, 53, 53-64. [CrossRef]

65. Debono, A.; Yeats, T.H.; Rose, J.K.; Bird, D.; Jetter, R.; Kunst, L.; Samuels, L. Arabidopsis LTPG is a glycosylphosphatidylinositol-anchored lipid transfer protein required for export of lipids to the plant surface. Plant Cell 2009, 21, 1230-1238. [CrossRef]

66. Edqvist, J.; Blomqvist, K.; Nieuwland, J.; Salminen, T.A. Plant lipid transfer proteins: Are we finally closing in on the roles of these enigmatic proteins? J. Lipid Res. 2018, 59, 1374-1382. [CrossRef] [PubMed]

67. Beisson, F.; Li-Beisson, Y.; Pollard, M. Solving the puzzles of cutin and suberin polymer biosynthesis. Curr. Opin. Plant Biol. 2012, 15, 329-337. [CrossRef]

68. Serna, L. Crosstalk among hormones and signaling networks during stomatal development in Arabidopsis hypocotyls. AIMS Mol. Sci. 2016, 3, 550-559. [CrossRef]

69. Hung, F.Y.; Chen, J.H.; Feng, Y.R.; Lai, Y.C.; Yang, S.; Wu, K. Arabidopsis JMJ29 is involved in trichome development by regulating the core trichome initiation gene GLABRA3. Plant J. 2020. [CrossRef]

70. de la Canal, L.; Pinedo, M. Extracellular vesicles: A missing component in plant cell wall remodeling. J. Exp. Bot. 2018, 69, 4655-4658. [CrossRef]

71. Pollard, M.; Beisson, F.; Li, Y.; Ohlrogge, J.B. Building lipid barriers: Biosynthesis of cutin and suberin. Trends Plant Sci. 2008, 13, 236-246. [CrossRef] [PubMed]

72. Xia, Y.; Yu, K.; Navarre, D.; Seebold, K.; Kachroo, A.; Kachroo, P. The glabra1 mutation affects cuticle formation and plant responses to microbes. Plant Physiol. 2010, 154, 833-846. [CrossRef] [PubMed]

73. Schweizer, P.; Jeanguenat, A.; Whitacre, D.; Métraux, J.-P.; Mösinge, E. Induction of resistance in barley againstErysiphe graminisf. sp. hordeiby free cutin monomers. Physiol. Mol. Plant Pathol. 1996, 49, 103-120. [CrossRef]

74. Curvers, K.; Seifi, H.; Mouille, G.; De Rycke, R.; Asselbergh, B.; Van Hecke, A.; Vanderschaeghe, D.; Höfte, H.; Callewaert, N.; Van Breusegem, F. Abscisic acid deficiency causes changes in cuticle permeability and pectin composition that influence tomato resistance to Botrytis cinerea. Plant Physiol. 2010, 154, 847-860. [CrossRef] [PubMed]

75. Contento, A.L.; Bassham, D.C. Structure and function of endosomes in plant cells. J. Cell Sci. 2012, 125, 3511-3518. [CrossRef]

76. An, Q.; Huckelhoven, R.; Kogel, K.H.; van Bel, A.J. Multivesicular bodies participate in a cell wall-associated defence response in barley leaves attacked by the pathogenic powdery mildew fungus. Cell Microbiol. 2006, 8, 1009-1019. [CrossRef]

77. Fan, G.; Yang, Y.; Li, T.; Lu, W.; Du, Y.; Qiang, X.; Wen, Q.; Shan, W. A Phytophthora capsici RXLR effector targets and inhibits a plant PPIase to suppress endoplasmic reticulum-mediated immunity. Mol. Plant 2018, 11, 1067-1083. [CrossRef]

78. Kosma, D.K.; Bourdenx, B.; Bernard, A.; Parsons, E.P.; Lu, S.; Joubes, J.; Jenks, M.A. The impact of water deficiency on leaf cuticle lipids of Arabidopsis. Plant Physiol. 2009, 151, 1918-1929. [CrossRef] 
79. Cui, F.; Brosche, M.; Lehtonen, M.T.; Amiryousefi, A.; Xu, E.; Punkkinen, M.; Valkonen, J.P.; Fujii, H.; Overmyer, K. Dissecting Abscisic Acid Signaling Pathways Involved in Cuticle Formation. Mol. Plant 2016, 9, 926-938. [CrossRef]

80. Goren-Saglam, N.; Harrison, E.; Breeze, E.; Oz, G.; Buchanan-Wollaston, V. Analysis of the impact of indole-3-acetic acid (IAA) on gene expression during leaf senescence in Arabidopsis thaliana. Physiol. Mol. Biol. Plants 2020, 26, 733-745. [CrossRef]

81. Asghari, M.; Merrikhi, M.; Kavoosi, B. Methyl Jasmonate Foliar Spray Substantially Enhances the Productivity, Quality and Phytochemical Contents of Pomegranate Fruit. J. Plant Growth Regul. 2019. [CrossRef]

82. Yang, X.; Feng, T.; Li, S.; Zhao, H.; Zhao, S.; Ma, C.; Jenks, M.A.; Lü, S. CER16 inhibits post-transcriptional gene silencing of CER3 to regulate alkane biosynthesis. Plant Physiol. 2020, 182, 1211-1221. [CrossRef]

83. Yang, X.; Zhao, H.; Kosma, D.K.; Tomasi, P.; Dyer, J.M.; Li, R.; Liu, X.; Wang, Z.; Parsons, E.P.; Jenks, M.A.; et al. The Acyl Desaturase CER17 Is Involved in Producing Wax Unsaturated Primary Alcohols and Cutin Monomers. Plant Physiol. 2017, 173, 1109-1124. [CrossRef]

84. Pina-Mimbela, R.; Madrid, J.A.; Kumar, A.; Torrelles, J.B.; Rajashekara, G. Polyphosphate kinases modulate Campylobacter jejuni outer membrane constituents and alter its capacity to invade and survive in intestinal epithelial cells in vitro. Emerg. Microbes Infect. 2015, 4, 1-9. [CrossRef]

85. Ammar, E.-D.; Fulton, D.; Bai, X.; Meulia, T.; Hogenhout, S.A. An attachment tip and pili-like structures in insect-and plant-pathogenic spiroplasmas of the class Mollicutes. Arch. Microbiol. 2004, 181, 97-105. [CrossRef]

86. Forcat, S.; Bennett, M.H.; Mansfield, J.W.; Grant, M.R. A rapid and robust method for simultaneously measuring changes in the phytohormones ABA, JA and SA in plants following biotic and abiotic stress. Plant Methods 2008, 4, 16. [CrossRef]

87. Trapnell, C.; Williams, B.A.; Pertea, G.; Mortazavi, A.; Kwan, G.; Van Baren, M.J.; Salzberg, S.L.; Wold, B.J.; Pachter, L. Transcript assembly and quantification by RNA-Seq reveals unannotated transcripts and isoform switching during cell differentiation. Nat. Biotechnol. 2010, 28, 511-515. [CrossRef]

(C) 2020 by the authors. Licensee MDPI, Basel, Switzerland. This article is an open access article distributed under the terms and conditions of the Creative Commons Attribution (CC BY) license (http://creativecommons.org/licenses/by/4.0/). 